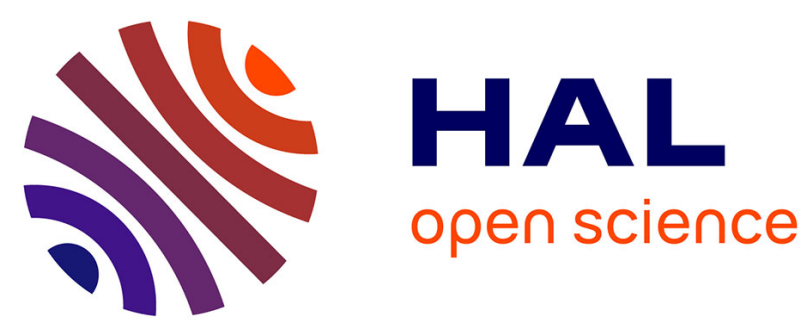

\title{
Tsunami Impact on a Detached Breakwater: Insights from Two Numerical Models
}

Denis Morichon, Volker Roeber, Manuel Martin Medina, Florian Bellafont, Stéphane Abadie

\section{- To cite this version:}

Denis Morichon, Volker Roeber, Manuel Martin Medina, Florian Bellafont, Stéphane Abadie. Tsunami Impact on a Detached Breakwater: Insights from Two Numerical Models. Journal of Waterway, Port, Coastal, and Ocean Engineering, 2021, 147 (2), pp.05021001. 10.1061/(ASCE)WW.19435460.0000622 . hal-03200067

\section{HAL Id: hal-03200067 https://hal-univ-pau.archives-ouvertes.fr/hal-03200067}

Submitted on 16 Apr 2021

HAL is a multi-disciplinary open access archive for the deposit and dissemination of scientific research documents, whether they are published or not. The documents may come from teaching and research institutions in France or abroad, or from public or private research centers.
L'archive ouverte pluridisciplinaire HAL, est destinée au dépôt et à la diffusion de documents scientifiques de niveau recherche, publiés ou non, émanant des établissements d'enseignement et de recherche français ou étrangers, des laboratoires publics ou privés. 


\title{
Tsunami impact on a detached breakwater - insights from two numerical models
}

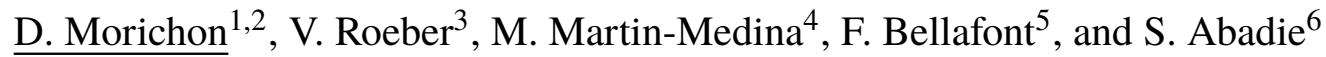 \\ ${ }^{1}$ Ph.D., Assist. Prof., Universite de Pau et des Pays de l'Adour, E2S UPPA, SIAME, Anglet, \\ France, 1 Allée du Parc Montaury- 64600-Anglet-France, denis.morichon@univ-pau.fr \\ ${ }^{2}$ corresponding author \\ ${ }^{3}$ Ph.D., Assist. Prof., Universite de Pau et des Pays de l'Adour, E2S UPPA, SIAME, chair \\ HPC-Waves, Anglet, France, 1 Allée du Parc Montaury- 64600-Anglet-France, \\ volker.roeber@univ-pau.fr \\ ${ }^{4}$ Ph.D., Universite de Pau et des Pays de l'Adour, E2S UPPA, SIAME, Anglet, France , 1 Allée du \\ Parc Montaury- 64600-Anglet-France, manuel.martinmedina@univ-pau.fr \\ ${ }^{5}$ Ph.D., Universite de Pau et des Pays de l'Adour, E2S UPPA, SIAME, Anglet, France , 1 Allée du \\ Parc Montaury- 64600-Anglet-France, bellafont.florian@univ-pau.fr \\ ${ }^{6}$ Ph.D.,Prof., Universite de Pau et des Pays de l'Adour, E2S UPPA, SIAME, Anglet, France, 1 \\ Allée du Parc Montaury- 64600-Anglet-France, stephane.abadie @ univ-pau.fr
}

\begin{abstract}
Tsunami waves are often very energetic and therefore pose a significant threat to coastal structures. However, most coastal defenses such as detached breakwaters are designed to protect against storm waves, with the consequence that tsunamis often lead to a catastrophic failure of these structures. This numerical study was inspired by the wave scenario, which occurred at Soma Port in Japan, during the 2011 Tohoku Tsunami where a combination of tsunami-type waves and shorter period undular bores caused severe damage to a detached caisson breakwater. The objective herein is to analyze the role, which undular bores play on breakwater stability in the case of a tsunami
\end{abstract}


propagating over a gentle slope into shallow water. Two complementary wave models - one of Boussinesq-type and the other of RANS-VOF-type - are used to compute the propagation of a representative tsunami composed of multiple waves components and their impact on a detached breakwater. The presence of an undular bore is controlled by the balance between wave nonlinearity and dispersion. Since the drawdown from the first wave reduces the water depth around the breakwater and leaves the structure almost completely exposed, only the second wave transforms into an undular bore. This causes wave breaking far offshore from the breakwater where a large amount of energy is dissipated ultimately resulting in much less destructive wave impact at the structure. The undular bore influences the wave loading on the breakwater, though the bulk of the wave loads and the excessive bearing pressures were computed for the long-lasting overtopping process of the first wave. These findings facilitate the damage assessment of detached breakwaters as they relate some specific tsunami features to structural stability and failure mechanisms. The results also provide information regarding the applicability and usefulness of different numerical modeling approach for the analysis of the stability of detached breakwaters under tsunamis. For this particular case, even depth-integrated numerical models provide conclusive solutions. To the authors' knowledge, this is the first numerical study addressing breakwater stability with respect to the impact of undular bores under tsunami conditions.

\section{INTRODUCTION}

The 2011 Tohoku Tsunami struck Japan in 2011 and caused severe damages to many offshore vertical breakwaters ranging from erosion of rubble-mound to partial displacement and total collapse of caissons. Several studies (Martin-Medina 2017, Mori and Takahashi 2012, Mikami et al. 2012) have shown that breakwater failure mechanisms were often related to the particular type of tsunami wave that varied along the Japanese coast due to local bathymetric features. For instance, the Iwate coast, which is characterized by deep water near the shore and steep bathymetric slopes, was mainly impacted by tsunami surges - similar to a quickly rising tide - that lead to the failure of the world's tallest breakwater at Kamaishi with a caisson height between $10 \mathrm{~m}$ and $15 \mathrm{~m}$ in a water depth of up to $60 \mathrm{~m}$. Contrary, in the shallow Sendai Bay, observations have shown that 
breakwaters near harbor entrances were impacted by short wave trains resembling the phenomenon of undular bores (see Fig. 2 in Murashima et al. 2012).

This study focuses on tsunami-like undular bore and their impact on coastal defenses. The propagation of undular bores has been observed in many geophyical phenomena including tides propagating in estuaries (Bonneton et al. 2015, Chanson 2010), dam-break flows (Treske 1994, Soares Frazao and Zech 2002, Kim and Lynett 2010) and long waves such as tsunami propagating in shallow waters (Matsuyama et al. 2007, Madsen et al. 2008). In the work presented in (Madsen et al. 2008), that states the solitary wave paradigm for tsunamis, the authors highlighted that when a long wave enters shallow water, its skewness and asymmetry increase. As the wave front steepens, the flow near the wave crest becomes slightly supercritical. At this stage, there is a balance between frequency dispersion and nonlinearity that can lead to the development of an undular bore. With further shoaling, controlled by the local bathymetry, the bore undulations can form a train of breaking waves that impact the coast and/or adjacent structures. Though the underlying tsunami wave would rather behave like a quickly rising tide, the superposed undular bore appears to be closer to swell or storm waves regarding their wavelength, steepness, and amplitude.

The effect of frequency dispersion on the generation of undular bores during the 1993 Southwest Hokkaido tsunami, which occured along the Okushiri island coast, has been shown experimentally and numerically in (Sato 1996). The occurrence of tsunami-type undular bores, near the coast, was also observed and documented in footage and photographs during the Indian Ocean Tsunami in 2004 (Glimsdal et al. 2006, Horrillo et al. 2006, Grue et al. 2008, Arcas and Segur 2012) and the Tohoku Tsunami (Murashima et al. 2012, Saito et al. 2014, Baba et al. 2015). In their studies, (Glimsdal et al. 2006) and (Horrillo et al. 2006), pointed out that the increase of tsunami steepness in shallow water contributed locally to the increase of dispersive effects, which lead to the generation of undular bores at some locations during the Indian Ocean Tsunami. They also showed that undular bores cannot be reproduced with conventional shallow water equations, and that non-linear dispersive models are required to accurately describe the full tsunami transformation in nearshore areas. In (Grue et al. 2008), the formation of undular bores in the shallow Strait of Malacca during 
the Indian Ocean Tsunami of 2004 was numerically investigated using a fully nonlinear and fully dispersive model, and a Korteweg-deVries model. Two different tsunami heights, the original one and half of its height, were studied. The results of their study show that a wave train appeared in both cases when the tsunami front reached a comparable wave slope of 0.0036 to 0.0038 . The dominant period of short waves in their numerical computations was observed to be slightly longer than 20 sec. In Sendai Bay, helicopter footage (see Fig. 2 in Murashima et al. 2012) shows a pronounced undular bore arriving at the coast during the second wave of the Tohoku Tsunami. (Baba et al. 2015) using a Boussinesq-type model computed the tsunami-induced inundation along the Sendai coast. Their study confirmed that the computation of tsunami-like undular bores requires to account for the balance between nonlinear and dispersive effects. They also showed that the maximum inundation extents computed by dispersive models is slightly smaller than that by long-wave models based on the Nonlinear Shallow Water Equations. According to their study, this latter type of model tends to concentrate large portions of the total energy around the leading wave front. A comprehensive study on the role of dispersion effects for several tsunami cases was conducted by (Glimsdal et al. 2013). Their work shows that the formation of undular bores can double the local tsunami height before reaching the coast. These various studies suggest that an accurate description of tsunami impact on coastal structures requires a precise description of the physical processes that govern the tsunami transformation phase.

Tsunami loading on coastal structures has been investigated through both laboratory experiments (Cross 1967, Ramsden 1996, Asakura et al. 2003, Ikeno et al. 2007, Nouri et al. 2010, Guler et al. 2015, Kihara et al. 2015) and numerical studies (Arikawa et al. 2012, Jianhong et al. 2013, McCabe et al. 2014, among others). Most of the numerical work is based on solutions from Navier-Stokes models describing the complexity of the interaction processes between fluid and structures. For instance, (Arikawa et al. 2012) used a realistic waveform of the Tohoku Tsunami as input for the Reynolds Averaged Navier-Stokes (RANS) CADMAS-SURF/3D model in order to study the particular failure mechanisms of the Kamaishi breakwater. In their study, they concluded that the breakwater failure was mainly caused by the difference in water level to either side of the 
breakwater and scouring around its foundation. Solitary waves were used in (Hsiao and Lin 2010) to represent tsunami waves impinging a coastal structures. They applied a RANS model to study wave transformation processes and forces acting on a seawall for three different solitary wave impacts: case (a) where the solitary wave breaks before arriving at the seawall, case (b) where the wave collapses directly into the seawall and a last case (c) where the wave only breaks after it has overtopped the seawall. In (Jianhong et al. 2013), a Volume Averaged Reynolds Averaged Navier-Stokes (VARANS) model, coupled with a Biot model, was used to investigate tsunami impacts on a vertical breakwater including interaction between free surface flow and runoff in the porous structure and the soil. This approach allows to compute pressure fields on the caisson, the rubble-mound, and the seabed. In this study, solitary waves were also used to represent the tsunami. (Jiang et al. 2016) carried out small-scale laboratory experiments of tsunami-like solitary waves impacting a rectangular seawall that were used to validate the model OpenFOAM solving the RANS equations. The validated model was then used to conduct a series of numerical experiments to investigate the flow field and wave pressures in dependence of the seawall dimensions and wave height. While most of the previously cited numerical studies on tsunami impact use solitary waves to represent the tsunami, their results should be interpreted with caution (Madsen et al. 2008). Indeed, the solitary wave approach is not strictly suitable to study storm wave impacts or single undulations traveling on top of tsunami like undular bores.

Previous studies have shown that undular bores can originate during the propagation of a tsunami depending on the local bathymetry. The contribution of these undulations to the runup envelop was demonstrated to be rather small compared to the influence of the main underlying tsunami. However, it is still unclear what role an undular bore can play with respect to the failure of breakwaters during the Indian Ocean Tsunami in 2004 and the Tohoku Tsunami in 2011. This study aims to address the influence of undular bores on breakwater stability through numerical solutions of a hypothetical tsunami case inspired by video observations taken at Soma Port at the southern end of Sendai Bay. The detached breakwater at Soma Port was originally designed to protect the port facilities from storm waves - tsunamis were not taken into account during the design process. 
The objective here is to identify the overall contribution of undular bores on the breakwater stability, rather than the exact reproduction of the wave processes at Soma Port. Therefore, the problem is reduced to a one-dimensional transect representing the main bathymetry features and the geometry of the detached Soma breakwater. The computed tsunami is composed of two waves as measured by a GPS buoy off Sendai Bay during the Tohoku Tsunami. Two complementary wave models, a Boussinesq-type and a RANS models, are used to compute the wave envelope's transformation and its impact on the breakwater. Horizontal forces and moments exerted on an idealized caisson breakwater are then computed for each wave to assess the caisson's stability under different loading conditions. The results are then analyzed and discussed.

\section{METHODOLOGY}

\section{Model Of Tsunami Propagation}

\section{Model description}

The propagation of tsunami-type waves and their transformation into undular bores are computed with the phase-resolving Boussinesq-type model BOSZ (Boussinesq Ocean \& Surf Zone model). The model was developed for the computation of nearshore waves, wave-driven currents, infragravity oscillations, ship wakes waves, near-field tsunamis and boulder/sediment transport (see for example Roeber et al. 2010a, Roeber and Cheung 2012, Roeber and Bricker 2015, Li et al. 2018, David et al. 2017). The governing equations are based on a conserved variable formulation of the popular equations by (Nwogu 1993). The solution structure covers the Nonlinear Shallow Water Equations (NSWE) as a subset of the governing equations with a Finite Volume scheme based on a Total Variation Diminishing (TVD) reconstruction method of up to $5^{\text {th }}$ order and a HLLC Riemann solver. This ensures robust and accurate computations of fast flows over irregular terrain including wet/dry boundaries. The frequency dispersion terms are based on a central-differential Finite Difference scheme. The time integration is carried out with Runge-Kutta schemes of up to $4^{\text {th }}$ order and adaptive time stepping. For most applications such as the present study, a $2^{\text {nd }}$ order time integration leads to converging results. Due to the presence of space-time derivatives of the evolution variables in the momentum equations, a system of equations have to be solved 
to extract the flow speed at the end of each time step in each of the momentum equations. The two systems are independent from each other with arising data-dependencies in only the $\mathrm{X}$ or the Y-direction, respectively, which facilitates parallel computation on supercomputers. In the $2 \mathrm{DH}$ horizontal plane, the X-direction is cross-shore and normal to the wavemaker and the Y-direction refers to the longshore orientation. Obviously, in a $1 \mathrm{DH}$ setting, where the computation is carried out along only one transect of cells, the problem reduces to only the X-direction.

Coastal structures are considered part of the impermeable bathymetry. The wave shape is input from the left boundary as a time series of free surface elevation. The flow velocity is based on long-wave assumptions according to the changes in water level at the boundary. This allows for near-perfect replication of the tsunami input conditions.

Wave breaking is a challenging problem for dispersive depth-integrated models. As the free surface steepens, nonlinearity increases, which is consequently balanced by the frequency dispersion terms. With no dissipative terms, the governing equations of Boussinesq-type and non-hydrostatic models do not explicitly hold for flow discontinuities present at the leading edge of breaking waves or bores. Conveniently, the numerical solution can still provide physically meaningful results, if the potentially arising artifacts (in extreme cases even instabilities) near the wave front are counter-measured or avoided. BOSZ restricts the development of overshoots through local and momentary deactivation of the dispersion terms over a few grid cells along the breaking wave front. The deactivation can be based on a momentum gradient threshold, i.e. a dynamic criterion, or a kinematic criterion based on a local free surface Froude number value, which is employed in this study. There are multiple methods to define the onset of breaking and most numerical codes are rather insensitive to the choice of criterion. The wave breaking problem become challenging, however, with a reduction of grid size.

Assuming quasi-hydrostatic flow conditions near the wave breaking front, the contribution of the dispersion terms in the governing equations is ignored momentarily in every cell where the Froude number $(F r)$ at the free surface exceeds 1.0. To provide a transitional regime, the magnitude of the dispersion terms is reduced from $100 \%$ to $0 \%$ for the range between $0.85<F r<1.0$, which 
was determined based on the results from the following validation case. The Froude number is calculated as $F r=\sqrt{u_{z}^{2}+v_{z}^{2}} / \sqrt{g(h+\eta)}$, where $u_{z}$ and $v_{z}$ denote the horizontal velocities in $\mathrm{X}$ and Y-direction, respectively, and $h$ the local water depth and $\eta$ the free surface elevation. Obviously, for 1D horizontal computations, the $y$-component is irrelevant.

In Nwogu's equation (Nwogu 1993), the flow velocity at any level in depth can be reconstructed through the prescribed velocity profile embedded in the governing equations. The velocity potential is expanded as a Taylor-series in the vertical coordinate, $z$. The approximation for frequency dispersion results from the truncation of the series at second-order, which leads to a quadratic variation for the horizontal velocity over depth, and a linear variation for the vertical velocity. With $z=\eta$, the free surface velocity is given by

$$
u_{z}=u_{z_{\alpha}}+\frac{1}{2}\left(z_{\alpha}^{2}-z^{2}\right)\left[\left(u_{z_{\alpha}}\right)_{x x}+\left(v_{z_{\alpha}}\right)_{x y}\right]+\left(z_{\alpha}-z\right)\left[\left(h u_{z_{\alpha}}\right)_{x x}+\left(h v_{z_{\alpha}}\right)_{x y}\right]
$$

$$
v_{z}=v_{z_{\alpha}}+\frac{1}{2}\left(z_{\alpha}^{2}-z^{2}\right)\left[\left(u_{z_{\alpha}}\right)_{x y}+\left(v_{z_{\alpha}}\right)_{y y}\right]+\left(z_{\alpha}-z\right)\left[\left(h u_{z_{\alpha}}\right)_{x y}+\left(h v_{z_{\alpha}}\right)_{y y}\right]
$$

The reduction of (Eq. 1) for $1 \mathrm{D}$ problems is trivial. It should be noted that $z_{\alpha}$ is the reference depth at which the horizontal velocities are evaluated. The position in the water column, $z_{\alpha}=-0.55502 \mathrm{~h}$ was suggested by (Simarro et al. 2013) and optimized for linear and nonlinear performance. Bottom friction is accounted for through a drag term based on the Manning coefficient. Though the code allows for a different Manning coefficient in each grid cell, a uniform value of $0.02 \mathrm{~s} / \mathrm{m}^{1 / 3}$ was chosen for this study following the results of a sensitivity analysis carried out with values ranging between 0 and $0.05 \mathrm{~s} / \mathrm{m}^{1 / 3}$. The selected value is consistent with the value used in the numerical study of (Baba et al. 2015), which also investigates the Tohoku tsunami propagation in the Sendai bay.

\section{Validation case}

The ability of BOSZ to compute the development of undular bores is tested with the laboratory experiments presented in (Matsuyama et al. 2007). This benchmarking test was also used for numerical validations in (Kim and Lynett 2010) and (Grilli et al. 2012). The test is well suited to 
analyze the capacity of a wave model to compute the propagation of long sinusoidal waves over shallow waters and their transformation into undular bores. The experiment was performed in a large wave flume of $205 \mathrm{~m}$ length, $3.4 \mathrm{~m}$ width and $4 \mathrm{~m}$ depth. The results of case 024 are used to validate BOSZ. This particular case is based on an incident wave with $0.03 \mathrm{~m}$ amplitude and $20 \mathrm{~s}$ period, propagating over a $1 / 200$ slope representing a continental shelf. The upstream boundary of the numerical domain is lined up with the wave gauge located at $x=80 \mathrm{~m}$ in the physical wavetank (Fig.3 in Matsuyama et al. 2007). The total length of the numerical domain from the upstream boundary to the end of the continental shelf is set to the same dimensions as the physical model. The free surface measured at the wave gauge is prescribed at the wave boundary in BOSZ. The grid size of the computational domain was set to $0.05 \mathrm{~m}$.

The free surface elevations obtained with the laboratory experiments and BOSZ are compared at two different locations (see first graph in Fig.1) in Fig.2. At $x=30 \mathrm{~m}$ from the shoreline, the model accurately reproduces the two undulations atop of the first wave, but the wave phase is slightly ahead compared to the laboratory experiments. For the second wave, the phase shift is reduced and the computed wave train agrees reasonably well with the experimental data. BOSZ then properly computes the undular bore formation and the propagation of the undulations, even though small amplitude differences are observed $(\simeq 1 \mathrm{~cm})$. The number and period of the undulations are well reproduced. Closer to shore $(x=49.2 \mathrm{~m})$, the BOSZ model computes the amplitude increase of the undulations of the first wave. The subsequent bore moves slightly slower than in the laboratory experiment. At this location, the height of the second undular bore $(\eta=0.05 \mathrm{~m})$ decreases with respect to the offshore location $(\eta=0.08 \mathrm{~m})$. This transformation is well modeled by BOSZ despite slight discrepancies in the amplitude and period of short waves.

Overall, this particular validation case shows that the generation and the subsequent evolution of undular bores from long waves can be generally computed by phase-resolving models such as BOSZ. The small discrepancies might be associated with the appropriateness of the input signal, which still remains unknown to some extent. 


\section{Model Of Tsunami Impact On Detached Breakwater}

The detailed interaction between the tsunami and the breakwater, represented by a porous media, is computed with the THETIS model that solves the RANS (Reynolds-Averaged Navier-Stokes) equations with a Volume Of Fluid (VOF) method to capture the interface evolution. THETIS was chosen to account for both the flow through the rubble mound breakwater and the uplift force induced under a caisson breakwater. The flow is considered incompressible and the continuity of fluid velocity is assumed through the interface. The turbulent flow terms are computed with the $k-\epsilon$ model, which was already chosen in similar previous studies (Nakayama and Kuwahara 1999, Hsu et al. 2002, del Jesus et al. 2012).

The Navier-Stokes equations are discretized on a fixed Cartesian grid using a finite volume formulation. Following (Patankar 1980), the finite volume formulation is then solved using a staggered mesh known as the Marker And Cells (MAC) method from (Harlow and Welch 1965). The coupling between velocity and pressure is solved using the augmented Lagrangian method (Fortin and Glowinski 1982). This is a minimization method under the constraint of the continuity equation, where the pressure, which is decoupled from the velocity, appears as a Lagrangian multiplier. THETIS has been modified by (Desombre et al. 2012) to model multiphase flows (water and air) inside porous mediums. The flow computation in the porous medium, considered as homogeneous, isotropic and immobile, is based on the Forchheimer equation that is an extension of the Darcy equation.

Several studies (Desombre et al. 2012, Mokrani and Abadie 2016, Kazolea et al. 2019, MartinMedina et al. 2018) have shown an extensive validation of THETIS for the computations of wave propagation and impact on coastal structures. Of particular interest for this paper is the validation presented in (Martin-Medina et al. 2017) to model wave impacts on a porous composite breakwater.

\section{Numerical Study Case Based On The Soma Breakwater}

\section{Set-up of the tsunami propagation model-BOSZ}

The study case is a synthetic scenario inspired by the Soma breakwater that was strongly damaged during the Tohoku Tsunami in 2011. Eyewithnesses have testified that undular bores 
have impinged on the breakwater during the arrival of the second wave that is consist with the helicopter footage taken over Sendai Bay at other location (see Fig. 2 in Murashima et al. 2012). Therefore, our semi-idealized case is of particular interest for studying not only the interaction between tsunami waves and local bathymetry where undular bores can originate, but also for investigating the breakwater stability for two different wave loading conditions.

In this study, a 1-D profile representing the geometry of the detached breakwater of Soma Port and the bathymetry off the port to a depth of $140 \mathrm{~m}$ (profile A-B in Fig.3(a)) is used to study the transformation of tsunamis and their impact on a detached caisson breakwater, which was built in intermediate water depth to protect against storm waves. The computational domain is $62 \mathrm{~km}$ long and composed of a grid with $10 \mathrm{~m}$ resolution, which is fine enough to properly reproduce the wavelength of the individual wave components of an undular bore. The bathymetry is displayed in Fig.3(b). The tsunami signal recorded by the GPS801 buoy (Fig.3(c)), which is the only GPS buoy off the Sendai Bay is imposed at the offshore boundary of the computational domain. The initial water level is set to $-0.16 \mathrm{~m}$ (relative to the mean water level), corresponding to the tidal level when the tsunami signal was recorded. The period and amplitude $\left(a_{i}\right)$ of the first wave are approximately $20 \mathrm{~min}$ and $6 \mathrm{~m}$, respectively. After the first wave, there is a significant water level drop of $-5 \mathrm{~m}$, followed by the arrival of the second wave with a height of $5 \mathrm{~m}$. Since the incident tsunami velocity imposed at the offshore boundary of the computational domain is not available from GPS buoy measurements, it is estimated using the shallow water approximation based on Airy wave theory, which relates the tsunami speed to only the local water depth. This approximation is confirmed by the study of (Baba et al. 2015), in which the tsunami wave forms determined from this buoy are compared to a Non Linear Shallow Water model and a Boussinesq-type model. The study reveals no discrepancies between the two wave models suggesting that the local effects of frequency dispersion were negligible at this particular water depth.

The computations of the entire tsunami propagation (nearly two hours) with BOSZ take almost 10 minutes on one Intel ${ }^{\circledR}$ Core $^{\mathrm{TM}}$ i7-5600U CPU @ 2.60GHz $\times 4$ (8 Go RAM). 
Set-up of the tsunami impact model-THETIS

The detailed computation of the wave-structure interaction is modeled using a one-way coupled approach. The extent of the tsunami impact model was reduced to a length of $4.5 \mathrm{~km}$ to focus the simulation on the wave arrival in the near-shore area and its interaction with the offshore breakwater. The set-up of the THETIS model and a zoom on the vertical breakwater geometry, a 1D profile, are displayed in Fig.4. The numerical domain is discretized in 439501 elements over an irregular mesh refined to a minimum at the breakwater of $20 \mathrm{~cm}$ in the horizontal and vertical directions. The water level and the velocity time series computed with the BOSZ model are used as input at the left boundary and an open boundary condition is imposed on the right side.

Initial tests showed that if the first and the second wave are modeled sequentially, numerical instabilities appear at the left boundary when the first reflected wave reaches this location because of the one-way coupling approach. As a workaround, THETIS was run separately for the first and second wave. The computation from BOSZ shows that the second wave occurred around $t=4400$ s. At that time, a strong return flow induced by the draw-down of the first wave has set in and the undular bore of the second wave has well developed (see Fig.5 and Fig.6). The initial water level on each side of the breakwater corresponds to the free surface elevation given by BOSZ at the end of the first wave, which is $-6.5 \mathrm{~m}$ on the offshore and $-1.5 \mathrm{~m}$ on the lee side of the breakwater. This set-up simplifies the interaction between the two waves but it retains the most relevant wave process, such as the draw-down flow.

Comparisons between free surface elevations computed with BOSZ and THETIS (see Fig. 3.14 and Fig. 3.15 in Martin-Medina 2017) reveal that the shape and velocity of the first wave are very similar. The maximum wave height computed with BOSZ at $t=3500 \mathrm{~s}$ reaches $14.5 \mathrm{~m}$ and $15 \mathrm{~m}$ for THETIS. Some differences appear only during the second wave propagation once the undular bore has developed, breaking of the two first undulations occurring earlier in THETIS than in BOSZ. However, it is worth to note that after the impact of the leading short waves, the two models are in good agreement to simulate the arrival and reflection of the second wave body at $4900 \mathrm{~s}$ and 5000 s, respectively. 
The computations of the interaction between the two waves and the breakwater with THETIS take nearly 10 days on 8 cores (DELL ${ }^{\mathrm{TM}}$ PowerEdge ${ }^{\mathrm{TM}}$ C6100).

\section{Results Analysis}

\section{Determination of undular bore characteristics}

The BOSZ results are first used to study the processes controlling the evolution of a long wave into an undular bore during the tsunami propagation. The analysis is based on the computation of the evolution of the maximum free surface slope $\left(\alpha_{m}\right)$ at the wave front and the Froude number ( Fr ) during the wave propagation from offshore until the first undulation appears. The maximum free surface slope represents the maximum local wave steepness of the wave front at any given time. (Grue et al. 2008) and (Bonneton et al. 2015) used this parameter to investigate the moment, at which an undular bore appears when a long wave such as a tsunami or tidal wave propagates into shallow coastal waters. The increase of the maximum free surface slope is linked to the transition between the wave regime and the undular bore regime. As concluded in (Grue et al. 2008) and (Bonneton et al. 2015), undulations start to generate when a threshold of free surface gradient is passed. The Froude number of the front, also used in (Bonneton et al. 2015), allows for characterization of the bore intensity and flow regime. These parameters are defined as follows:

$$
\begin{gathered}
\alpha_{m}=\frac{\left(\frac{\delta \eta}{\delta t}\right)_{\max }}{c_{b}}=\max \left(\frac{\delta \eta}{\delta x}\right) \\
F r=\frac{\left|u_{0}-c_{b}\right|}{\sqrt{g h_{0}}}
\end{gathered}
$$

where $u_{0}$ is the average fluid velocity before the bore arrives, $c_{b}$ the bore celerity, $h_{0}$ the water depth at the wave front and $\eta$ the free surface height.

For the numerical computations presented in the paper, the maximum wave slope is the maximum calculated at every point between the wave front (where the free surface height passes $1 \%$ of the tsunami body height) and the wave crest. The Froude number refers to the tsunami front. 


\section{Computation of wave loading and caisson stability}

The analysis of the stability of the caisson breakwater exposed to hydrodynamic loading is computed from the THETIS results for each wave. This analysis is first performed based on the computation of a safety factor against sliding (S.F.) defined by :

$$
S . F .=\frac{\mu W_{e}}{F_{h}-F_{h, \text { harbour }}}
$$

where $\mu$ refers to a friction coefficient representing the friction between the caisson and the porous foundation of the breakwater. $W_{e}$ denotes the effective weight of the caisson. The symbols $F_{h}$ and $F_{h, \text { harbour }}$ refer to the forces acting on the left and right side of the caisson, respectively. Following (Goda 2010), the friction coefficient $\mu$ was set to 0.6. The effective weight of the caisson $W_{e}$ is given by :

$$
W_{e}=W-F_{u}
$$

where $W$ denotes the weight of the caisson equal to $5290 \mathrm{kN}$ and $F_{u}$ the uplift force acting on the bottom of the caisson. All forces are computed according to:

$$
F=\sum P_{j} A_{j}
$$

in which $P_{j}$ is the pressure acting on the $j^{\text {th }}$ cell of area $A_{j}$.

The forces are then used to compute the moments about the heel of the caisson namely, the horizontal overturning moments, $M_{h}$ and $M_{h \text {,harbour }}$, the uplift overturning moment, $M_{u}$, and the stabilizing moment, $M_{w}$ allowing to compute a safety factor against overturning (S.F.m) following the expression:

$$
\text { S.F.m }=\frac{M_{w}-M_{u}}{M_{h}-M_{h, \text { harbour }}}
$$

In addition, the bearing capacity of the rubble mound breakwater is estimated by computing the 
bearing pressure on the breakwater foundation at the heel of the caisson following the formulation presented in (Goda 2010). First, the moment $M_{e}$ exerted on the heel of the caisson due to the resultant force of all the loads applied on the caisson is computed according to:

$$
M_{e}=M_{w}-M_{u}-M_{h}
$$

Knowing the normal force $W_{e}$ and the moment $M_{e}$, the horizontal distance $t_{e}$ between the heel and the normal force $W_{e}$ is given by:

$$
t_{e}=\frac{M_{e}}{W_{e}}
$$

The bearing pressure at the heel $p_{e}$ can then be calculated by the following expression (Goda 2010):

$$
p_{e}=\frac{2 W_{e}}{3 t_{e}} \text { if } t_{e} \leq B / 3
$$

$$
p_{e}=\frac{2 W_{e}}{B}\left(2-3 \frac{t_{e}}{B}\right) \quad \text { if } t_{e}>B / 3
$$

where $B$ is the width of the caisson.

\section{RESULTS}

\section{Tsunami Propagation}

\section{Modeling of the first and second wave}

The evolution of the free surface elevations of the tsunami, composed of two waves, that was computed with the BOSZ model is shown in Fig.5. The first wave is characterized by a length of $30 \mathrm{~km}$ and low steepness. When reaching the breakwater, this wave starts to overtop the structure $(t=3500 \mathrm{~s})$ without generating an impulsive collision. No undulation is observed atop of this first wave. After this first wave, the water level drops and the second wave arrives. In contrast to the first wave, the second wave is traveling in much shallower water at its leading edge results in a 
shortening and steepening of the wave. This evolution of the wave form is accompanied by the appearance of clear undulations (Fig.6) along the wave front about $14 \mathrm{~km}$ (in the middle of the flat region) from the breakwater. These undulations are very short $(\simeq 100 \mathrm{~m})$ and of up to $10 \mathrm{~m}$ amplitude (e.g. at $t=4250 \mathrm{~s}$ ). The development of the undular bore at $t=4000 \mathrm{~s}$ doubled the height of the second wave, which initially was $5 \mathrm{~m}$ near the coast at $t=3750 \mathrm{~s}$.

\section{Study of undular bore generation}

The variation of the maximum free surface slope of the wave front $\left(\alpha_{m}\right)$ and the first undular bore amplitude $\left(a_{u} / a_{i}\right)$, non-dimensionalized by the initial first tsunami amplitude, are illustrated in Fig. 7 for the first and second wave. The first wave presents an initial $\alpha_{m}$ of $3 \times 10^{-4}$ that slowly grows up to reach the value of $3 \times 10^{-3}$ when the wave starts interacting with the breakwater. As shown before, this first wave overtopped the breakwater without having evolved into an undular bore during its propagation. For the second wave, the initial $\alpha_{m}$ is $9 \times 10^{-4}$ (Fig. 7, bottom panel). The values of $\alpha_{m}$ rapidly increases with $x$, reaching the value of $9 \times 10^{-3}$ at $x=40000 \mathrm{~m}$ when the wave starts propagating over the nearly flat part of the seabed and first undulations appear. Once these undulations are present their amplitude continues to grow up to about $x=52000 \mathrm{~m}$ when $a_{u} / a_{i}$ decreases near the shore due to the depth-limited breaking process.

The spatial evolution of the Froude number during the tsunami propagation is displayed in Fig. 8 together with $\alpha_{m}$. For the two waves, the overall variation of the Froude number is mostly attributed to the sudden changes in the bathymetry. Thus, for the first wave, $F r$ increases with $x$ and reaches the value of 1.04 at the end of the first slope region $(x=22000 \mathrm{~m})$. Then, $F r$ keeps increasing slightly up to about 1.1 when the wave travels over the second section of the bed that is steeper. In the third and nearly flat region, the wave slows down and the $F r$ decreases again up 1.04. From this moment on, the Froude number progressively grows towards a maximum value of 1.2 while the wave approaches the coast. A similar evolution of $F r$, but with overall lower values, is obtained for the second wave during its propagation offshore. While the $F r$ values are close to the values computed for the first wave in the first section, they remain quasi-constant $(F r \geq 1.02)$ during the propagation above the second bed section of $16 \mathrm{~km}$ long. After this section, the $\mathrm{Fr}$ 
number suddenly decreases below 1 at $x=42000 \mathrm{~m}$. This location corresponds to the location where the second wave transforms into an undular bore (Fig.7, bottom panel) followed by a rapid increase of Fr up to 1.27. Closer to the shore, at $x=49000 \mathrm{~m}, F r$ drops when the reflected first wave meets the shoreward propagating second wave.

\section{Tsunami Impact On The Breakwater}

In this section, the THETIS results are used to investigate the impact of the first and second wave on the hypothetical breakwater. First, the analysis focuses on the propagation and interaction of the tsunami with the structure, considering only the last $2 \mathrm{~km}$ of the THETIS domain. Then, the impact forces, overturning moments, safety factor values and bearing pressure are calculated in order to study the potential failure mechanisms of the breakwater due to the tsunami impact.

\section{Tsunami interaction with the breakwater}

The study of the free surface elevations of the first wave (Fig.9, left panels (a)) shows that it reaches a maximum height of $15 \mathrm{~m}$ at $t=3500 \mathrm{~s}$. This wave generates a constant overflow over the caisson that produces a large vortex at the lee side of the breakwater as shown in Fig.9(c). The evolution of the free surface of the second wave highlights the effect of the nearshore bathymetry on the undular bore (Fig.9, right panels (b)). At $t=4500 \mathrm{~s}$, the first two waves of the undular bore have broken far from the coast $(2.5 \mathrm{~km})$. As the undulations break offshore of the breakwater, their height is significantly reduced by the time they hit the structure. Close to the breakwater, the maximum undulation height is close to $4 \mathrm{~m}$. These undulations ride atop of the core wave, which is about $5 \mathrm{~m}$ high. When the undular bore reaches the breakwater, the impact generates a turbulent front and successive broken short waves impinge on the breakwater $(t=4700 \mathrm{~s})$. After the impact of the undulations, the trailing edge of the tsunami reaches the breakwater and is reflected $(t=4900$ $\mathrm{s}$ and $5000 \mathrm{~s})$.

\section{Tsunami loading}

The temporal variations of the horizontal and uplift forces ( $F_{h}$ and $F_{u}$ respectively) acting on the caisson breakwater during the impact of the tsunami are plotted in Fig.10 for the two waves 
with the corresponding safety factors $(S F)$. Regarding the first wave, the horizontal force reaches a maximum value of $2400 \mathrm{kN}$. Significant uplift forces are also generated $\left(F_{u} \simeq 2600 \mathrm{kN}\right)$ due to the fluid pressure inside the rubble-mound. Fluctuations in the $F_{u}$ values appear from $t=3400 \mathrm{~s}$, when the wave starts overtopping the breakwater causing overflow $(9(\mathrm{c}))$. As mentioned before, this flow generates a large eddy on the lee side of the breakwater that acts directly on the rubble-mound toe and produces significant pressure oscillations. During the impact of the second wave, the wave loading on the caisson can be divided into two phases: first the impact of the undulations followed by the arrival of the tsunami body. During the first phase, the impacts of the sequence of short waves are clearly observed in the $F_{h}$ signal, with maximum values around $500 \mathrm{kN}$. The uplift force signal also shows the successive impacts of these undulations with a maximum load of $1300 \mathrm{kN}$. During the second phase, which lasts longer, larger horizontal force values are reached with a maximum of $F_{h}=900 \mathrm{kN}$. Similar behavior is also found for the uplift force with a maximum value of $1750 \mathrm{kN}$.

\section{Caisson stability}

The stability of the caisson during the tsunami impact is first assessed by calculating the safety factor $(S F)$ related to sliding forces computed in the previous section and by considering the stabilizing loads such as water at rest and the water mass above the caisson from to the overtopping discharge. A $S F$ value below 1.0 means that the caisson might be in unstable condition. For the first wave, $S F$ values stay slightly below 1.0 for a long period of time (200 s). On the opposite, $S F$ never reaches the threshold value of 1.0 during the impact of the undular bore associated with the second wave (minimum value around 4).

The caisson stability with respect to overturning is plotted in Fig.11. The overturning moments due to the destabilizing forces present the same behavior in time as the horizontal and uplift forces illustrated in Fig.10. The safety factor associated to overturning (S.F.m) is calculated as before by taking the stabilizing moments into account that are generated by the overtopping discharge and the still water at the harbor side. S.F.m values above 1.0 (a minimal value of 1.4) are obtained during the arrival of the first wave. For the second wave, S.F.m values remain far from the stability limit of 1.0 (7.0 is the minimal value). 
Finally, the time evolution of the bearing pressure at the heel of the caisson is shown in Fig.12. For the first wave, the highest pressure $(780 \mathrm{kPa})$ is obtained when the overtopping discharge is maximum. This value does not exceed the critical value of $800 \mathrm{kPa}$ (Uezono and Odani 1987), but the design limit of $600 \mathrm{kPa}$ (Goda 2010) is exceeded for a long period of time (300 s). For the second wave transformed into an undular bore, the bearing pressure is less significant $(\simeq 300 \mathrm{kPa})$ than for the first wave and does not exceed the design limit.

\section{DISCUSSION}

This study presents results from numerical model of particular processes that govern the transformation of tsunamis in shallow water and their impact on a detached breakwater. The computed tsunami conditions are similar to those, which occurred during the Tohoku Tsunami in Sendai Bay off the port of Soma. The modeling work is based on a one-way coupling strategy between two wave models allowing for description of the most relevant processes including dispersive and non-linear effects during the propagation phase and dynamic wave loading during the impact - including the contribution of flow under the rubble mound of a breakwater. The results of the study provide new insights related to the specific wave processes that can locally originate under tsunamis propagating over gentle slopes. The results help to identify the appropriate modeling strategies to assess the stability of a caisson breakwater in case of the investigated type of tsunami impact.

\section{Tsunami Transformation Processes}

The results from the Boussinesq model confirm that frequency dispersion can be a major factor for the tsunami transformation processes as previously shown by (Glimsdal et al. 2006), (Horrillo et al. 2006), (Grue et al. 2008) and (Saito et al. 2014). The computations of the free surface show that for a waveform similar to the one measured by the GPS801 buoy off of Soma Port during the Tohoku Tsunami, the first wave did not develop any undulation even close to the breakwater. In contrast, for the second and steeper wave, which has an initial maximum elevation slope $\left(\alpha_{m}\right)$ of $9 \times 10^{-4}$, a clear undular bore appears when $\alpha_{m}$ increases up to the value of $9 \times 10^{-3}$. In order to clarify whether the $\alpha_{m}$-value can constitute a threshold value, at which undular bores can appear, two additional numerical runs have been carried out with BOSZ over the same bathymetric 
configuration. In the first run, the initial wave amplitude is half of the original signal, and twice that value for the second run. The initial $\alpha_{m}$ are respectively $4.5 \times 10^{-4}$ and $1.8 \times 10^{-3}$. The undular bores appear when $\alpha_{m}$ reaches $9 \times 10^{-3}$, and $1 \times 10^{-2}$ respectively for the first and second runs. These results are consistent with the numerical study of (Grue et al. 2008), where it was shown that undular bores occurred in the Strait of Malacca when the maximum elevation slope exceeded a critical value between 0.0036 and 0.0038 for two cases with different wave amplitudes (5.2 m and $2.6 \mathrm{~m})$.

The two waves also present some discrepancies in terms of Froude number evolution during their propagation, with higher values observed for the first wave in overall. This difference is mainly caused by the return flow that accompanies the drawdown of the first wave and opposes the propagation of the second wave (Eq. 3). Closer to the shore, $\mathrm{Fr}$ rapidly increases after the formation of the undular bore while it remains relatively constant for the first wave. When the first undulations appear, $\mathrm{Fr}$ is about 1.0 and then increases to 1.2 before the undulations start breaking before the Fr-number increases. Such behavior was previously reported by (Treske 1994) and (Soares Frazao and Zech 2002). In their studies, they show that undulations appear for $F r$ values between 1.0 and 1.28 , and that undular bores develop into steep turbulent fronts for higher values. This suggests that in the Soma case, the first wave, which also presents $F r$ values above 1.0, could have evolved into an undular bore. However, other studies such as (Treske 1994), (Soares Frazao and Zech 2002) and (Chanson 2010) using a dambreak to generate a bore showed that the undulations only appear for a steep wave front. The low gradient of the first wave's initial front slope explains why no undulations appeared. This result confirms that $\alpha_{m}$ controls the formation of undulations whereas the Froude number mostly governs the type of wave regime.

\section{Breakwater Failure Mechanisms}

The numerical computations performed with the RANS-VOF model THETIS provide detailed information about impact forces acting on a caisson breakwater that can be used to study the potential causes of breakwater failures for scenarios similar to the one from Soma Port. First, the calculations reveal that the largest forces from overturning moments and bearing stresses are 
reached during the overtopping of the first wave. During this overtopping phase, the water level above the top of the caisson remains extremely high, $>10 \mathrm{~m}$, for a long period of time $(\simeq 10 \mathrm{~min})$. Consequently, the safety factor for sliding failure reaches values close to 1.0 during this stage. However, the safety factor values are not low enough to conclude that the horizontal forces on the caisson caused sliding during the impact of the first wave. This applies even more for the second wave, which evolves into an undular bore, since the the safety factor remains much higher than unity $(\simeq 4)$. This result is counter-intuitive at first as the breakwater was almost completely exposed after the drawdown that followed the recession of the first wave. In fact, the short waves of the undular bore started breaking $2 \mathrm{~km}$ offshore of the structure, leading to a substantial dissipation of wave energy far from the breakwater, and thus a reduction of the impact forces. Interestingly, excessive bearing pressures were computed at the heel of the caisson during the interaction of the first wave with the structure. This reduction of rubble mound bearing capacity combined with the high overturning moments could have contributed to the destabilization of the caisson. Furthermore, the strong tsunami overtopping during the first wave could also have scoured the lee side of the rubble-mound and thus reduced the adherence between the caisson and its foundation.

\section{Breakwater Stability Assessment With a Boussinesq-type wave model}

The study of the caisson stability based on the results from THETIS have shown that the characteristics of the impact are mainly controlled by the long lasting overtopping stage followed by a series of short broken waves without generating an impulsive impact. This suggests that a Boussinesq type wave model, such as BOSZ, can be used to assess the overall stability of the caisson for this particular case. Complementary computations were then performed to verify this hypothesis. The different forces acting on the caisson were derived from the water level given by BOSZ assuming hydrostatic presure as displayed in Fig. 13.

Since the flow inside the rubble mound cannot be solved with a depth-integrated model, in which the breakwater is represented as an impermeable element of the bathymetry, the uplift force is obtained assuming a triangular distribution of the pressure acting underneath the fictitious caisson (Fig. 13). The limits of this distribution are given by the hydrostatic pressures computed 
on each side of the caisson. For this specific tsunami impact, characterized by a rather slow wave structure interaction, the hydrostatic pressure assumption may work well. Indeed, in wave impact, the contribution of the dynamic pressure is known to matter only where the free surface is locally very steep. The first wave structure interaction displayed in Fig.9 (left pannels (a)) is associated with a slowly varying upstream flat free surface. For this type of interaction, the total pressure may deviate from the hydrostatic case only in the down stream recirculating region (Fig. 9, pannel (c)). The second wave impact is globally similar for the low frequency part, but also involves several bores. Oumeraci et al. 2001 show that for broken bores, as evidenced in Fig.9 (right pannels (b)), the force generated on the structure does not involve any pressure peak and the deviation from the hydrostatic pressure may also be limited.

Forces and safety factor computed from BOSZ are compared with those obtained with THETIS in Fig.10. In overall, the time evolution of the horizontal and vertical forces are very similar for the first wave with a slight overestimation of the horizontal force in BOSZ that leads to slightly lower safety factor values. In contrast, discrepancies between the two models are more pronounced for the second wave. First, the undular bore computed with BOSZ reaches the breakwater shortly after (about two minutes) the one computed with THETIS. The oscillations of the horizontal and uplift forces corresponding to the contribution of each short wave from the undular bore are well simulated by BOSZ with a slight overestimation. Once again, this induces a reduction of the safety factor values up to 2.8 , which, however, remain well above the critical threshold for safety. This confirms that the contribution of the dynamic pressure to the horizontal forces acting on the caisson, which is implicitly accounted for in THETIS, is negligible compared to the hydrostatic component. However, this result must be interpreted with caution since the leading short waves of the second wave broke before reaching the caisson.

Finally, the comparisons between BOSZ and THETIS reveal that for tsunami conditions similar to those computed in this study, a depth-integrated model can provide realistic estimates of tsunami loadings acting on a detached breakwater. This suggests that dispersive depth-integrated models can not only be used to assess overtopping risk (Hu et al. 2000, Roeber et al. 2010b, McCabe et al. 
2014), but can also be applied to give a first estimate of tsunami loadings and breakwater stability.

\section{CONCLUSIONS}

Two complementary wave models, a Boussinesq-type and a RANS-VOF models, were used to study the transformation of a tsunami composed of two waves. The computations include the propagating over a gentle continental shelf and the impact on a detached caisson-type breakwater for conditions similar to those observed at Soma Port during the Tohoku Tsunami. The following conclusions can be drawn from this work:

- The computations carried out with a Boussinesq-type model show that for this particular case only the second tsunami wave transformed into an undular bore. The hypothetical scenario is based on overall shape of the seabed and the detached breakwater at Soma Port, where video footage was taken that confirms these findings. The first undulations start to appear about $14 \mathrm{~km}$ offshore from the breakwater when the maximum free surface slope $\left(\alpha_{m}\right)$ at the wave front exceeds the critical value of $9 \times 10^{-3}$ in an area with gently sloping bathymetry. For the first wave, the front steepness remains lower than this threshold value preventing the development of undulation.

- The results of the RANS-VOF model show that the forces acting on the caisson are largest during the overtopping process of the first wave that lasted for several minutes. The impact of the second wave is characterized by the broken short waves of the undular bore followed by the impact of the main underlying tsunami surge. The hydrodynamic loadings on the caisson are larger during the surging phase than by the undular bore. The sliding and overturning safety factor are found to be lowest during the surging phase but still greater than 1 , suggesting that the hypothetical breakwater in the computations would have likely survived the impact of the entire second wave. The safety factor computed over the duration of the first wave is slightly below 1 . It is therefore likely that excessive bearing pressure (780 kPa) at the heel of the caisson during the long lasting overtoping of the first wave (300 s) caused the collapse of the breakwater. In addition, the reduction of rubble mound bearing 
capacity combined with the high overturning moment could have lead to the caisson's instability.

- For the tsunami conditions computed in this study, it is important to notice that due to the drawdown of the first wave the subsequent second wave transformed into an undular bore. This train of waves started breaking far offshore and underwent substantial dissipation before it reached the breakwater. Consequently, the undular bore itself only marginally contributed to the destabilization of the caisson breakwater for this particular case. However, further work should be carried out to address the role of undular bores under different tsunami scenarios and for different types of breakwaters.

- Dispersive depth-integrated models such as the Boussinesq-type model BOSZ are an attractive option for the assessment of breakwater stability at very low computational cost. In addition to their capability to compute tsunami evolutions over large domains and long periods of time, these models can provide reasonable first estimates of wave loadings. For a more detailed assessment of tsunami loadings on breakwaters, it is recommended to compute the full interaction between the waves and the structures at high resolution with a Navier-Stokes-type model.

\section{DATA AVAILABILITY STATEMENT}

The source codes of Thetis and BOSZ can be provided for scientific studies upon request.

\section{ACKNOWLEDGEMENTS}

This work was funded by the FP7 EU research program ASTARTE (Grant No.:603839) and the PIA RSNR French program TANDEM (Grant No.: ANR-11-RSNR-00023-01). Volker Roeber acknowledges financial support from Isite program Energy Environment Solutions (E2S), Communauté d'Agglomération Pays Basque (CAPB) and the Communauté Région Nouvelle Aquitaine (CRNA) for the chair position HPC-Waves.

\section{REFERENCES}


Arcas, D. and Segur, H. (2012). "Seismically generated tsunamis.” Phil. Trans. R. Soc. A, 370(1964), $1505-1542$.

Arikawa, T., Sato, M., Shimosako, K., Hasegawa, I., Yeom, G.-S., and Tomita, T. (2012). "Failure mechanism of kamaishi breakwaters due to the great east japan earthquake tsunami." Coastal engineering proceedings, 1(33), 1-13.

Asakura, R., Iwase, K., Ikeya, T., Takao, M., Kaneto, T., Fujii, N., and Ohmori, M. (2003). “The tsunami wave force acting on land structures." Coastal Engineering 2002: Solving Coastal Conundrums, World Scientific, 1191-1202.

Baba, T., Takahashi, N., Kaneda, Y., Ando, K., Matsuoka, D., and Kato, T. (2015). "Parallel implementation of dispersive tsunami wave modeling with a nesting algorithm for the 2011 tohoku tsunami." Pure and Applied Geophysics, 172(12), 3455-3472.

Bonneton, P., Bonneton, N., Parisot, J.-P., and Castelle, B. (2015). "Tidal bore dynamics in funnelshaped estuaries.” Journal of Geophysical Research: Oceans, 120(2), 923-941.

Chanson, H. (2010). "Undular tidal bores: basic theory and free-surface characteristics.” Journal of Hydraulic Engineering, 136(11), 940-944.

Cross, R. H. (1967). “Tsunami surge forces.” Journal of the waterways and harbors division, 93(4), 201-234.

David, C. G., Roeber, V., Goseberg, N., and Schlurmann, T. (2017). “Generation and propagation of ship-borne waves-solutions from a boussinesq-type model.” Coastal Engineering, 127, 170-187.

del Jesus, M., Lara, J. L., and Losada, I. J. (2012). “Three-dimensional interaction of waves and porous coastal structures: Part I: Numerical model formulation.” Coastal Engineering, 64, $57-72$.

Desombre, J., Morichon, D., and Mory, M. (2012). "Simultaneous surface and subsurface air and water flows modelling in the swash zone." Coastal Engineering Proceedings, 1(33), 1-12.

Fortin, M. and Glowinski, R. (1982). Méthodes de lagrangien augmenté: applications à la résolution numérique de problèmes aux limites, Vol. 28. Dunod Paris.

Glimsdal, S., Pedersen, G., Atakan, K., Harbitz, C., Langtangen, H., and Lovholt, F. (2006). 
"Propagation of the dec. 26, 2004, indian ocean tsunami: Effects of dispersion and source characteristics." International Journal of Fluid Mechanics Research, 33(1), 57-72.

Glimsdal, S., Pedersen, G. K., Harbitz, C. B., and Løvholt, F. (2013). "Dispersion of tsunamis: does it really matter?." Natural hazards and earth system sciences, 13(6), 1507-1526.

Goda, Y. (2010). Random seas and design of maritime structures. World scientific.

Grilli, S. T., Harris, J. C., Shi, F., Kirby, J. T., Bakhsh, T. S. T., Estibals, E., and Tehranirad, B. (2012). "Numerical modeling of coastal tsunami impact dissipation and impact." Coastal Engineering Proceedings, 1(33), 1-12.

Grue, J., Pelinovsky, E., Fructus, D., Talipova, T., and Kharif, C. (2008). "Formation of undular bores and solitary waves in the strait of malacca caused by the 26 december 2004 indian ocean tsunami." Journal of Geophysical Research: Oceans, 113(C5), 1-14.

Guler, H. G., Arikawa, T., Oei, T., and Yalciner, A. C. (2015). "Performance of rubble mound breakwaters under tsunami attack, a case study: Haydarpasa port, istanbul, turkey." Coastal Engineering, 104, 43-53.

Harlow, F. H. and Welch, J. E. (1965). "Numerical calculation of time-dependent viscous incompressible flow of fluid with free surface." The Physics of Fluids, 8(12), 2182-2189.

Horrillo, J., Kowalik, Z., and Shigihara, Y. (2006). "Wave dispersion study in the indian oceantsunami of december 26, 2004.” Marine Geodesy, 29(3), 149-166.

Hsiao, S.-C. and Lin, T.-C. (2010). "Tsunami-like solitary waves impinging and overtopping an impermeable seawall: Experiment and rans modeling." Coastal Engineering, 57(1), 1-18.

Hsu, T.-J., Sakakiyama, T., and Liu, P. L.-F. (2002). “A numerical model for wave motions and turbulence flows in front of a composite breakwater." Coastal Engineering, 46(1), 25-50.

Hu, K., Mingham, C. G., and Causon, D. M. (2000). "Numerical simulation of wave overtopping of coastal structures using the non-linear shallow water equations." Coastal Engineering, 41(4), $433-465$.

Ikeno, M., Matsuyama, M., Sakakiyama, T., and Yanagisawa, K. (2007). "Effects of soliton fission and wave breaking on tsunami force acting on breakwater." Coastal Engineering 2006: (In 5 
Volumes), World Scientific, 5162-5174.

Jiang, C., Liu, X., Yao, Y., Deng, B., and Chen, J. (2016). "Numerical investigation of tsunami-like solitary wave interaction with a seawall." Journal of Earthquake and Tsunami, 11(1), 1-18.

Jianhong, Y., Dongsheng, J., Ren, W., and Changqi, Z. (2013). "Numerical study of the stability of breakwater built on a sloped porous seabed under tsunami loading." Applied Mathematical Modelling, 37(23), 9575-9590.

Kazolea, M., Filippini, A., Ricchiuto, M., Abadie, S., Martin-Medina, M., Morichon, D., Journeau, C., Marcer, R., Pons, K., LeRoy, S., et al. (2019). "Wave propagation, breaking, and overtopping on a $2 \mathrm{~d}$ reef: A comparative evaluation of numerical codes for tsunami modelling." European Journal of Mechanics-B/Fluids, 73, 122-131.

Kihara, N., Niida, Y., Takabatake, D., Kaida, H., Shibayama, A., and Miyagawa, Y. (2015). "Largescale experiments on tsunami-induced pressure on a vertical tide wall." Coastal Engineering, 99, $46-63$.

Kim, D.-H. and Lynett, P. J. (2010). "Dispersive and nonhydrostatic pressure effects at the front of surge." Journal of Hydraulic Engineering, 137(7), 754-765.

Li, N., Yamazaki, Y., Roeber, V., Cheung, K. F., and Chock, G. (2018). "Probabilistic mapping of storm-induced coastal inundation for climate change adaptation." Coastal Engineering, 133, $126-141$.

Madsen, P. A., Fuhrman, D. R., and Schäffer, H. A. (2008). "On the solitary wave paradigm for tsunamis." Journal of Geophysical Research-Oceans, 113(C12), 1-22.

Martin-Medina, M. (2017). "Tsunami wave interaction with a coastal structure. Focus on the Tohoku tsunami case and the flip-through impact." Doctoral dissertation, Université de Pau et des Pays de l'Adour.

Martin-Medina, M., Abadie, S., Mokrani, C., and Morichon, D. (2018). "Numerical simulation of flip-through impacts of variable steepness on a vertical breakwater." Applied Ocean Research, $75,117-131$.

Martin-Medina, M., Abadie, S., and Morichon, D. (2017). "Validation of a navier-stokes model to 
study flip-through impacts on a composite breakwater." La Houille Blanche, 5, 49-55.

Matsuyama, M., Ikeno, M., Sakakiyama, T., and Takeda, T. (2007). "A study of tsunami wave fission in an undistorted experiment." Tsunami and Its Hazards in the Indian and Pacific Oceans, Springer, 617-631.

McCabe, M., Stansby, P. K., Rogers, B. D., and Cunningham, L. S. (2014). “Boussinesq modelling of tsunami and storm wave impact." Proceedings of the Institution of Civil Engineers-Engineering and Computational Mechanics, 167(3), 106-116.

Mikami, T., Shibayama, T., Esteban, M., and Matsumaru, R. (2012). "Field survey of the 2011 Tohoku earthquake and tsunami in Miyagi and Fukushima prefectures." Coastal Engineering Journal, 54(01), 1250011-1-1250011-26.

Miyajima, S. (2015). "Damage to Port and Port-related Facilities by the 2011 off the Pacific coast of Tohoku Earthquake.” Report No. 798, National Institute for Land and Infrastructure Management.

Mokrani, C. and Abadie, S. (2016). "Conditions for peak pressure stability in VOF simulations of dam break flow impact." Journal of Fluids and Structures, 62, 86-103.

Mori, N. and Takahashi, T. (2012). "Nationwide post event survey and analysis of the 2011 Tohoku earthquake tsunami." Coastal Engineering Journal, 54(01), 1250001-1-1250001-27.

Murashima, Y., Koshimura, S., Oka, H., Murata, Y., Fujima, K., Sugino, H., and Iwabuchi, Y. (2012). "Numerical simulation of soliton fission in 2011 tohoku tsunami using nonlinear dispersive wave model, (in japanese with english abstract)." Journal of Japan Society of Civil Engineers, Ser. B2 (Coastal Engineering), 68(2), I_206-I_210.

Nakayama, A. and Kuwahara, F. (1999). "A macroscopic turbulence model for flow in a porous medium." Transactions-American Society of Mechanical Engineers Journal of Fluids Engineering, 121, 427-433.

Nouri, Y., Nistor, I., Palermo, D., and Cornett, A. (2010). "Experimental investigation of tsunami impact on free standing structures.” Coastal Engineering Journal, 52(01), 43-70.

Nwogu, O. (1993). "Alternative form of Boussinesq equations for nearshore wave propagation." Journal of Waterway, Port, Coastal, and Ocean Engineering, 119(6), 618-638. 
Oumeraci, H., Kortenhaus, A., Allsop, W., de Groot, M., Crouch, R., Vrijling, H., and Voortman, H. (2001). Probabilistic design tools for vertical breakwaters. CRC Press.

Patankar, S. (1980). Numerical heat transfer and fluid flow. CRC Press.

Ramsden, J. D. (1996). "Forces on a vertical wall due to long waves, bores, and dry-bed surges." Journal of Waterway, Port, Coastal, and Ocean Engineering, 122(3), 134-141.

Roeber, V. and Bricker, J. D. (2015). "Destructive tsunami-like wave generated by surf beat over a coral reef during typhoon haiyan." Nature Communications, 6(1), 1-9.

Roeber, V. and Cheung, K. F. (2012). "Boussinesq-type model for energetic breaking waves in fringing reef environments." Coastal Engineering, 70, 1-20.

Roeber, V., Cheung, K. F., and Kobayashi, M. H. (2010a). "Shock-capturing Boussinesq-type model for nearshore wave processes." Coastal Engineering, 57(4), 407-423.

Roeber, V., Yamazaki, Y., and Cheung, K. F. (2010b). "Resonance and impact of the 2009 Samoa tsunami around Tutuila, American Samoa." Geophysical Research Letters, 37(21), 1-8.

Saito, T., Inazu, D., Miyoshi, T., and Hino, R. (2014). "Dispersion and nonlinear effects in the 2011 Tohoku-Oki earthquake tsunami." Journal of Geophysical Research: Oceans, 119(8), $5160-5180$.

Sato, S. (1996). "Numerical simulation of 1993 southwest Hokkaido earthquake tsunami around Okushiri Island.” Journal of Waterway, Port, Coastal, and Ocean Engineering, 122(5), 209-215.

Simarro, G., Orfila, A., and Galan, A. (2013). "Linear shoaling in Boussinesq-type wave propagation models." Coastal Engineering, 80, 100-106.

Soares Frazao, S. and Zech, Y. (2002). "Undular bores and secondary waves-Experiments and hybrid finite-volume modelling." Journal of Hydraulic Research, 40(1), 33-43.

Treske, A. (1994). "Undular bores (favre-waves) in open channels-Experimental studies.” Journal of Hydraulic Research, 32(3), 355-370.

Uezono, A. and Odani, H. (1987). "Planning and construction of the rubble mound for a deep water breakwater: the case of the Kamaishi bay mouth breakwater." Chapter 4.1 of Coastal and Ocean Geotechnical Engineering. The Japanese Geotechnical Society. 


\section{List of Figures}

1 BOSZ computation of the undular bore propagation. The initial water level is set to $0 m$. The free surface signal recorded at $x=80 m$ (see Fig. 3 in Matsuyama et al. 2007) during the experiments is imposed as boundary condition. . . . . . . . . . 32

2 Free surface $(\eta(m))$ evolution in time at ch17 $(x=30 m)$ and $\operatorname{ch} 10(x=49.2 m)$. Laboratory experiments (black) and BOSZ computations (blue) . . . . . . . . . 33

3 Numerical set-up of BOSZ.(a): Location of the Soma Port, profile A-B of the BOSZ computation and nearest GPS buoy around Sendai Bay.(b): Bathymetry along profile A-Band (c): Tsunami signal recorded at the GPS buoys.(Map data by OpenStreetMap, under ODbL) . . . . . . . . . . . . . . . . . 34

4 Numerical set-up of the Navier-Stokes computations with dimensions of a vertical breakwater and its porous rubble-mound. The set-up was inspired by the detached breakwater at Soma Port (bottom and breakwater profile derived from field survey provided by the Japanese Ministry of Land, Infrastructure, Transport and Tourism (Miyajima 2015). . . . . . . . . . . . . . . . . . 35

5 Propagation of the first and second tsunami with BOSZ. The initial water level is set to $-0.16 \mathrm{~m}$. Time with respect to the beginning of the computation. . . . . . . 36

6 Propagation of the undular bore generated atop the second tsunami with BOSZ. Time from the beginning of the computation. . . . . . . . . . . . . . 37

7 Evolution in space of the maximum elevation slope $\alpha_{m}(--)$ and first undulation bore amplitude $a_{u} / a_{i}(\mathrm{x} \mathrm{x})$. First (top panel) and second (middle panel) tsunami. . . 38

8 Evolution in space of the maximum elevation slope $\alpha_{m}(--)$ and Froude number $\mathrm{Fr}$ (. .). First (top panel) and second (middle panel) tsunami. . . . . . . . . . . . . . . 39 
9 Volume fraction of the first (a) and second (b) tsunami (undular bore) propagating near-shore computed with THETIS. (a) $t=3000 s, 3250 s, 3500 s, 3750 s, 4000 s$ and $4250 \mathrm{~s}$ from top to bottom. Water (dark gray) and air (white). (b) $t=4500 \mathrm{~s}$, $4600 s, 4700 s, 4800 s, 4900 s$ and $5000 s$ from top to bottom. Water (dark gray) and air (white). (c) Volume fraction and velocity (white arrows) of the large eddy generated during the first wave overtopping computed with THETIS ( $t=3750 \mathrm{~s})$. Water (dark gray) and air (light gray) . . . . . . . . . . . . . . . . 40

10 Horizontal $\left(F_{h}\right)$ and uplift forces $\left(F_{u}\right)$ and safety factor values (S.F.) computed from THETIS results for the first (top panels) and second wave (bottom panels). Results obtained with BOSZ are displayed with blue lines. The dash line represents when the safety factor is below 1.0 (unstable condition). . . . . . . . . . . . . 41

11 Horizontal $\left(M_{h}\right)$ and uplift moments $\left(M_{u}\right)$ and safety factor values against overturning (S.F.m) computed from THETIS results for the first (top panels) and second wave (bottom panels). The dash line represents when the safety factor is below 1.0

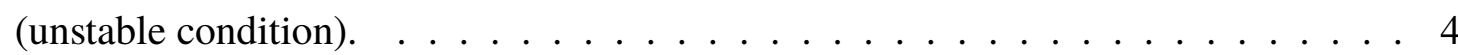

12 Bearing pressure estimated with THETIS for the first (left) and second wave (right).

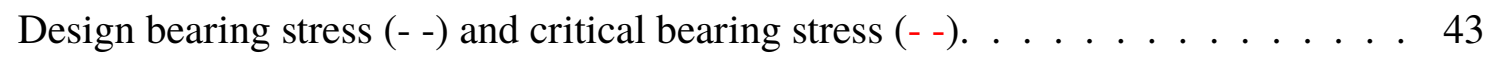

13 Forces acting on the caisson breakwater assuming hydrostatic pressure. . . . . . . . 44 

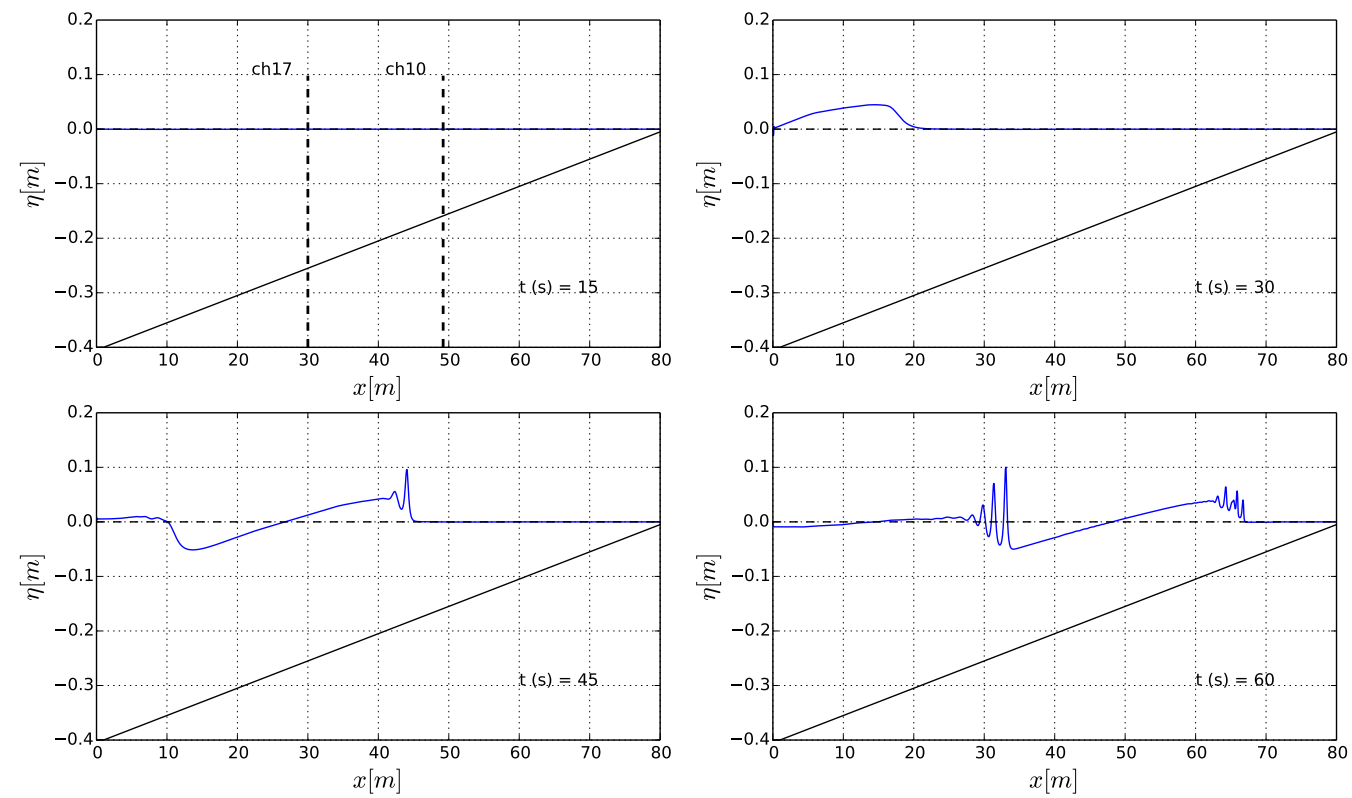

Fig. 1. BOSZ computation of the undular bore propagation. The initial water level is set to $0 m$. The free surface signal recorded at $x=80 \mathrm{~m}$ (see Fig. 3 in Matsuyama et al. 2007) during the experiments is imposed as boundary condition. 

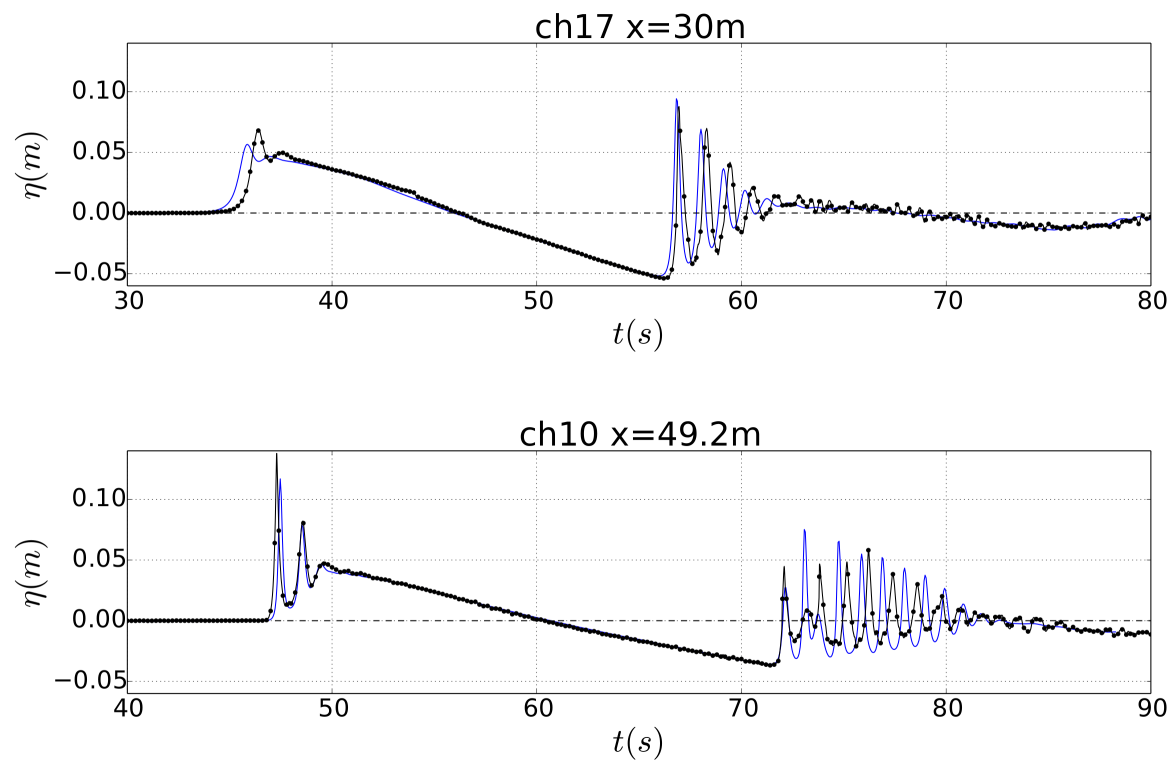

Fig. 2. Free surface $(\eta(m))$ evolution in time at $\operatorname{ch} 17(x=30 m)$ and $\operatorname{ch} 10(x=49.2 m)$. Laboratory experiments (black) and BOSZ computations (blue). 
(a)

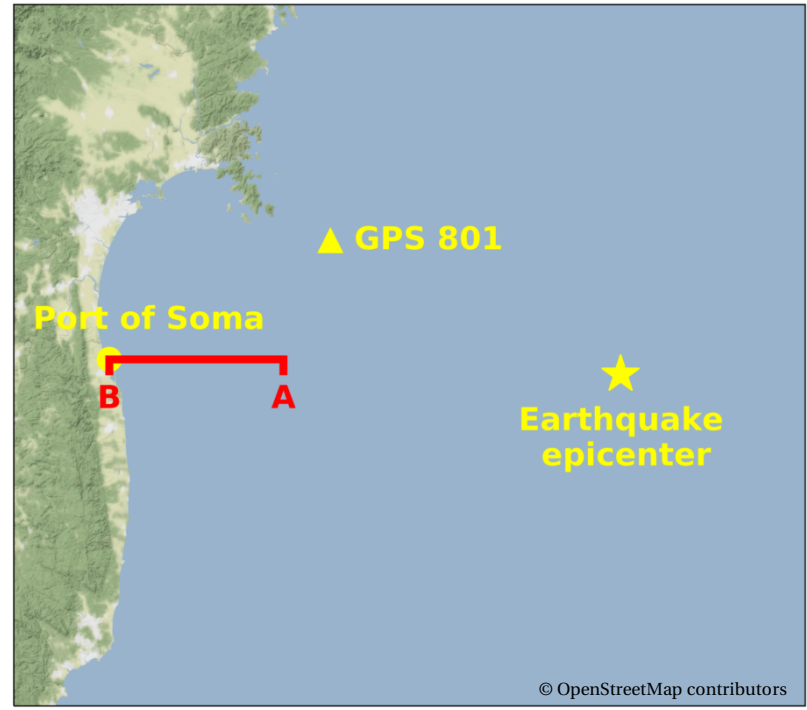

(b)

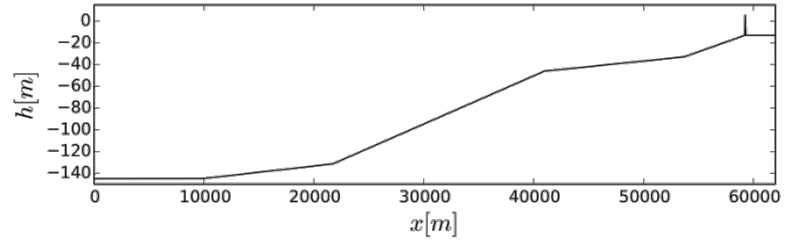

(c)

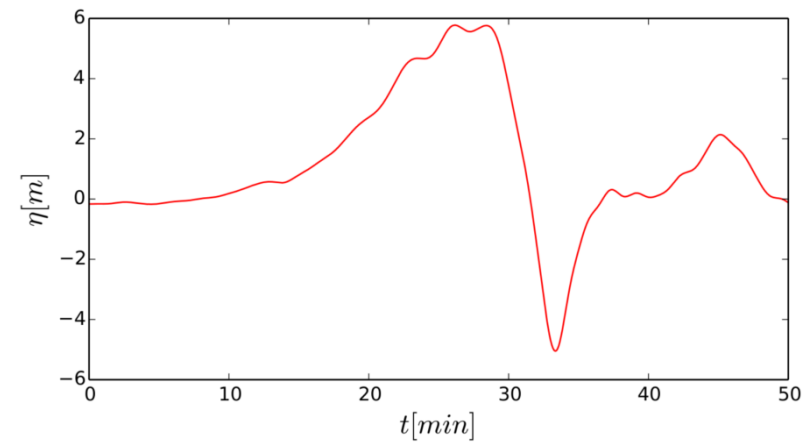

Fig. 3. Numerical set-up of BOSZ.(a): Location of the Soma Port, profile A-B of the BOSZ computation and nearest GPS buoy around Sendai Bay.(b): Bathymetry along profile A-Band (c): Tsunami signal recorded at the GPS buoys.(Map data by OpenStreetMap, under ODbL) 


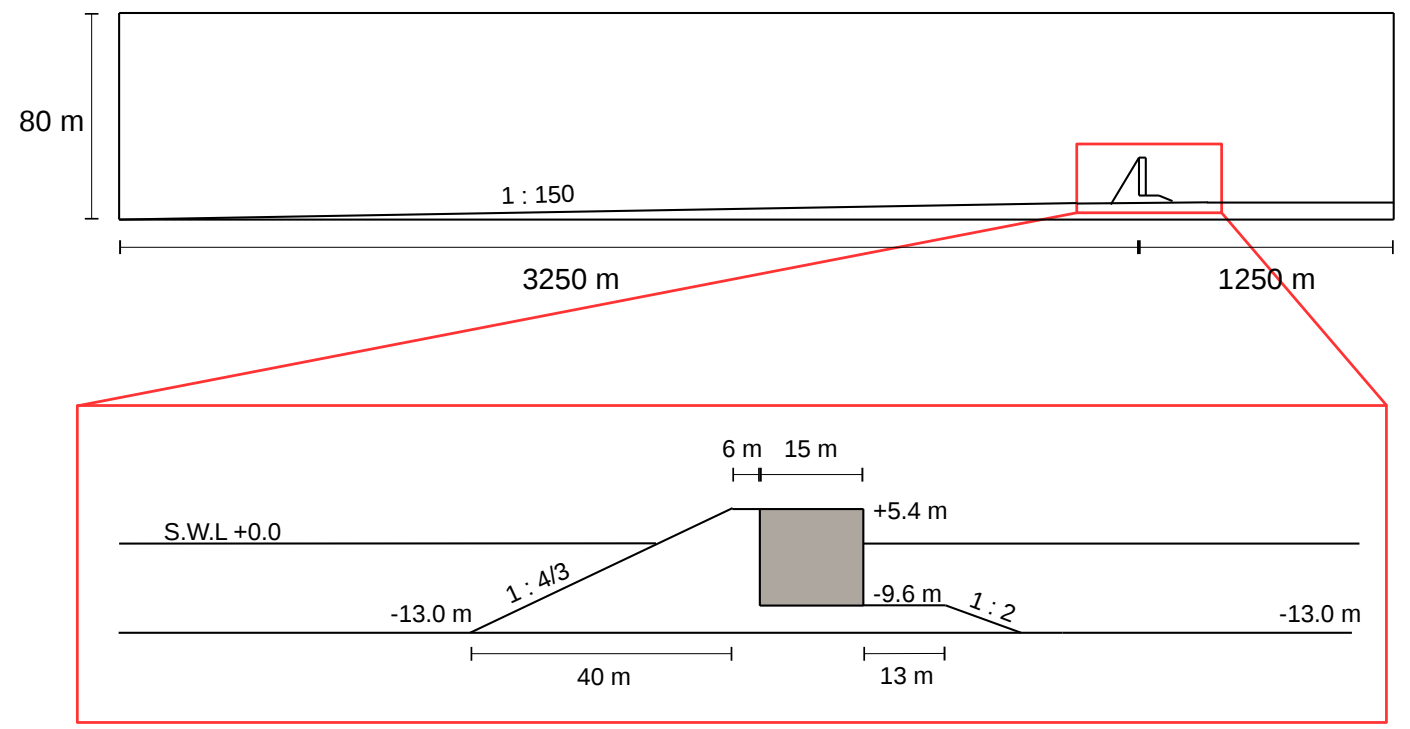

Fig. 4. Numerical set-up of the Navier-Stokes computations with dimensions of a vertical breakwater and its porous rubble-mound. The set-up was inspired by the detached breakwater at Soma Port (bottom and breakwater profile derived from field survey provided by the Japanese Ministry of Land, Infrastructure, Transport and Tourism (Miyajima 2015). 

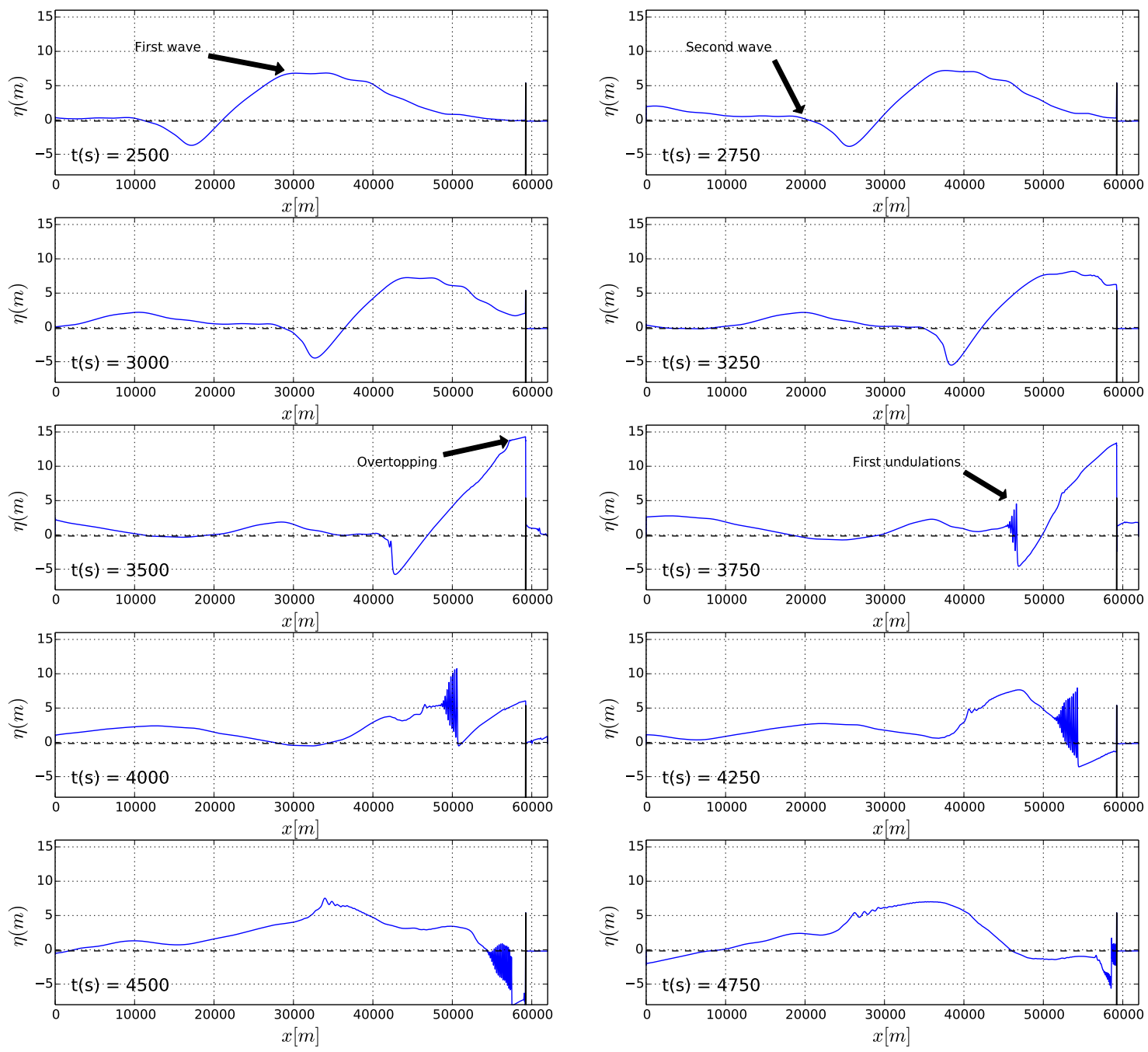

Fig. 5. Propagation of the first and second tsunami with BOSZ. The initial water level is set to $-0.16 \mathrm{~m}$. Time with respect to the beginning of the computation. 

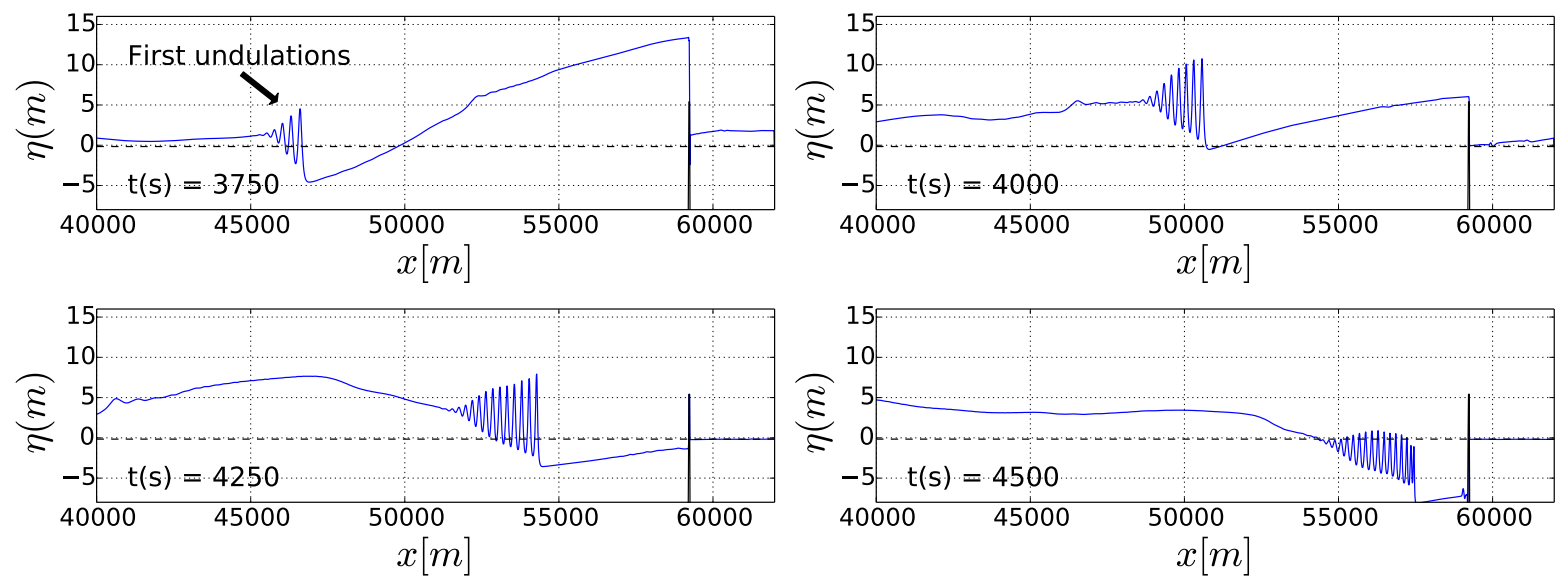

Fig. 6. Propagation of the undular bore generated atop the second tsunami with BOSZ. Time from the beginning of the computation. 

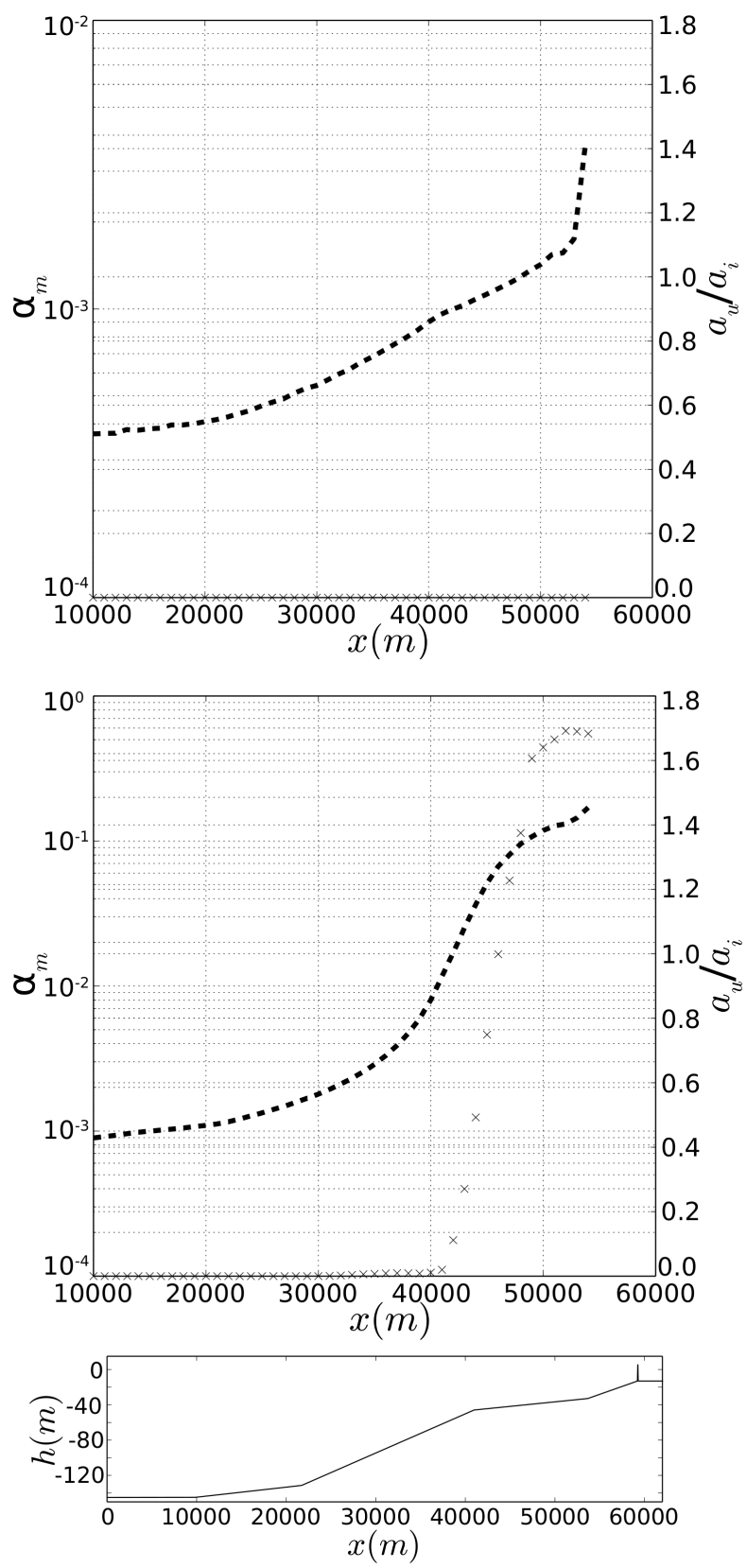

Fig. 7. Evolution in space of the maximum elevation slope $\alpha_{m}(--)$ and first undulation bore amplitude $a_{u} / a_{i}(\mathrm{x} x)$. First (top panel) and second (middle panel) tsunami. 

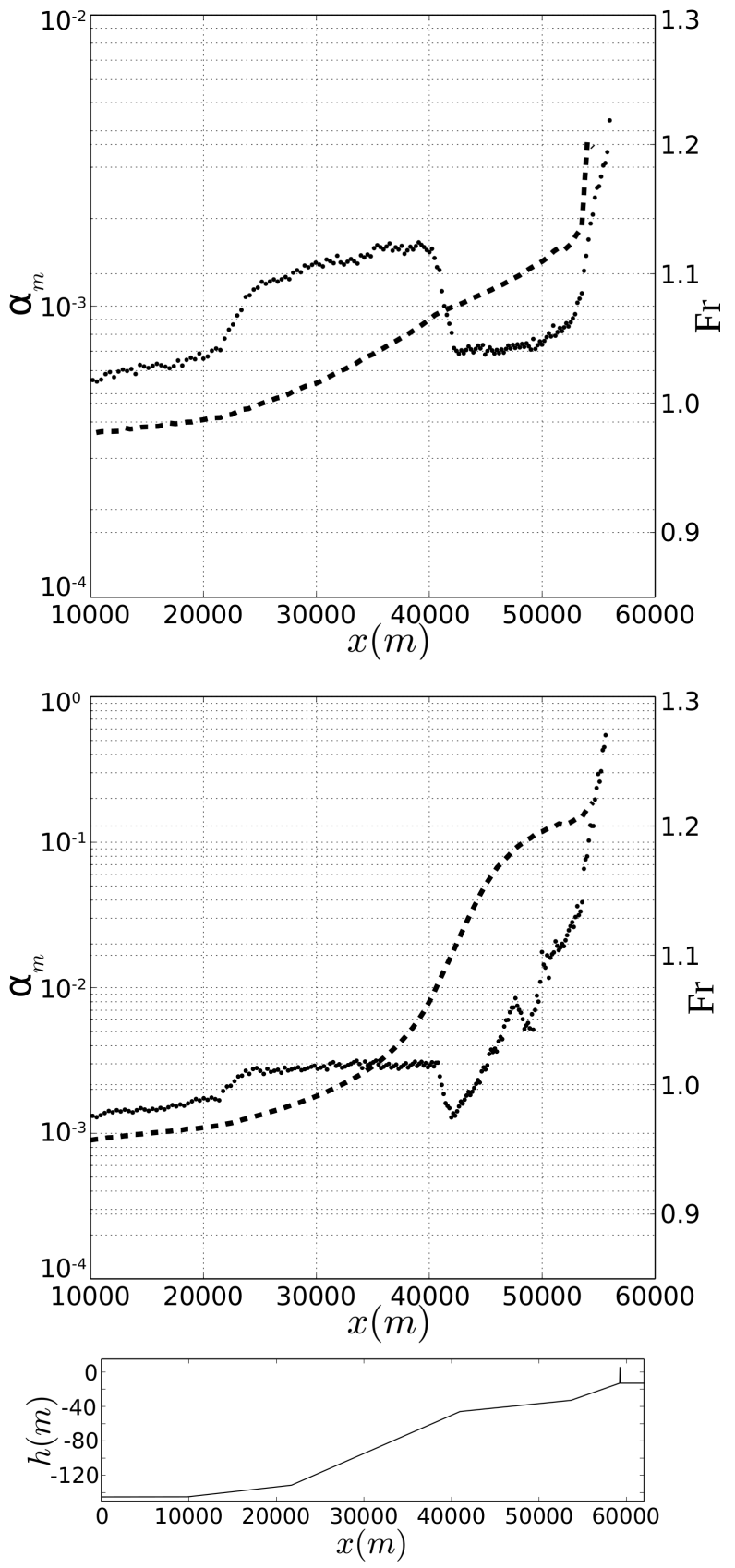

Fig. 8. Evolution in space of the maximum elevation slope $\alpha_{m}(--)$ and Froude number $\operatorname{Fr}($. .). First (top panel) and second (middle panel) tsunami. 
(a)
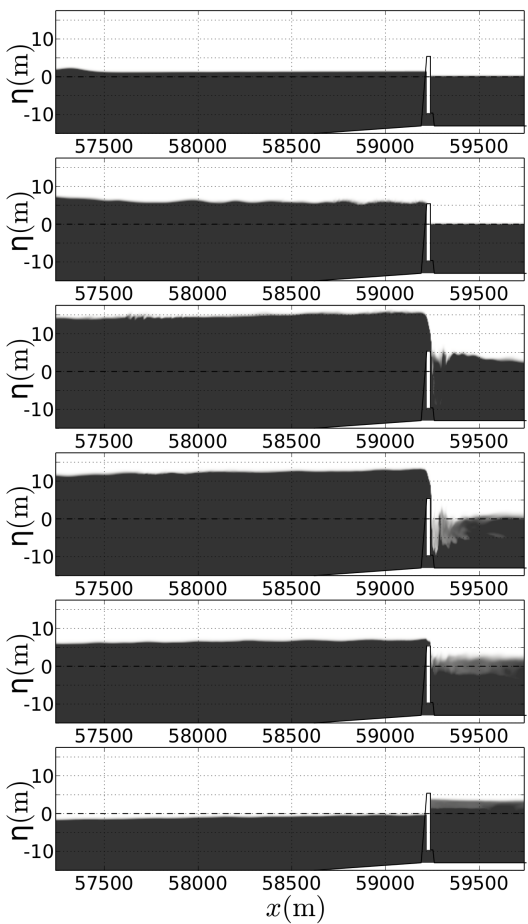

(b)
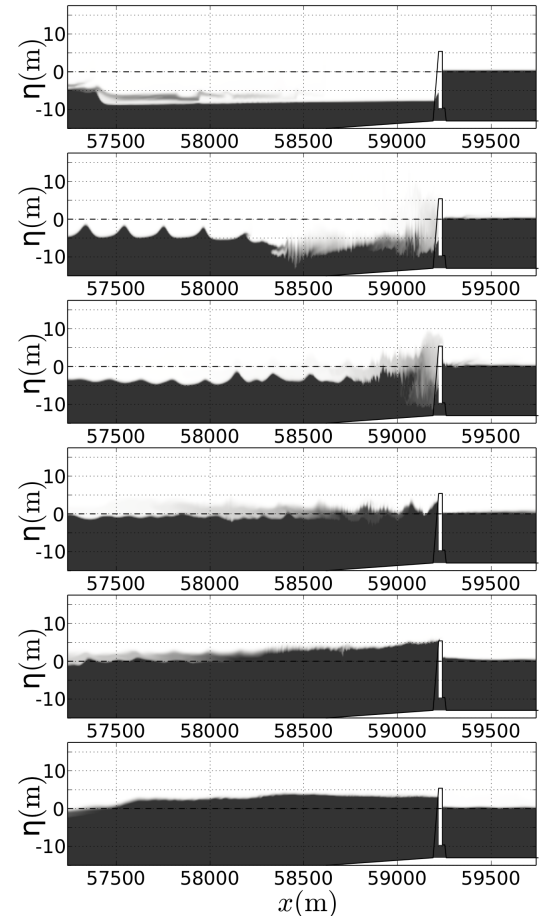

(c)

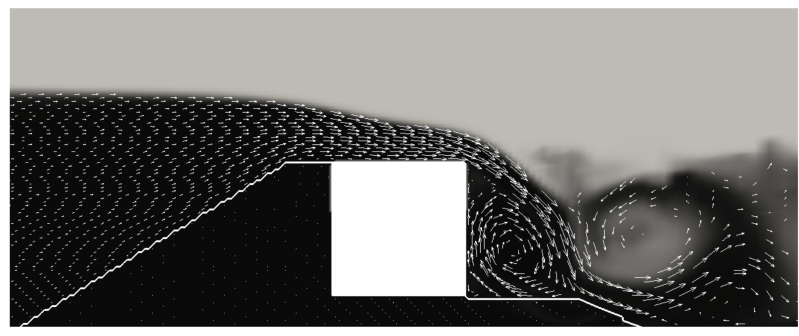

Fig. 9. Volume fraction of the first (a) and second (b) tsunami (undular bore) propagating near-shore computed with THETIS. (a) $t=3000 s, 3250 s, 3500 s, 3750 s, 4000 s$ and $4250 s$ from top to bottom. Water (dark gray) and air (white). (b) $t=4500 s, 4600 s, 4700 s, 4800 s, 4900 s$ and 5000s from top to bottom. Water (dark gray) and air (white). (c) Volume fraction and velocity (white arrows) of the large eddy generated during the first wave overtopping computed with THETIS $(t=3750 \mathrm{~s})$. Water (dark gray) and air (light gray). 

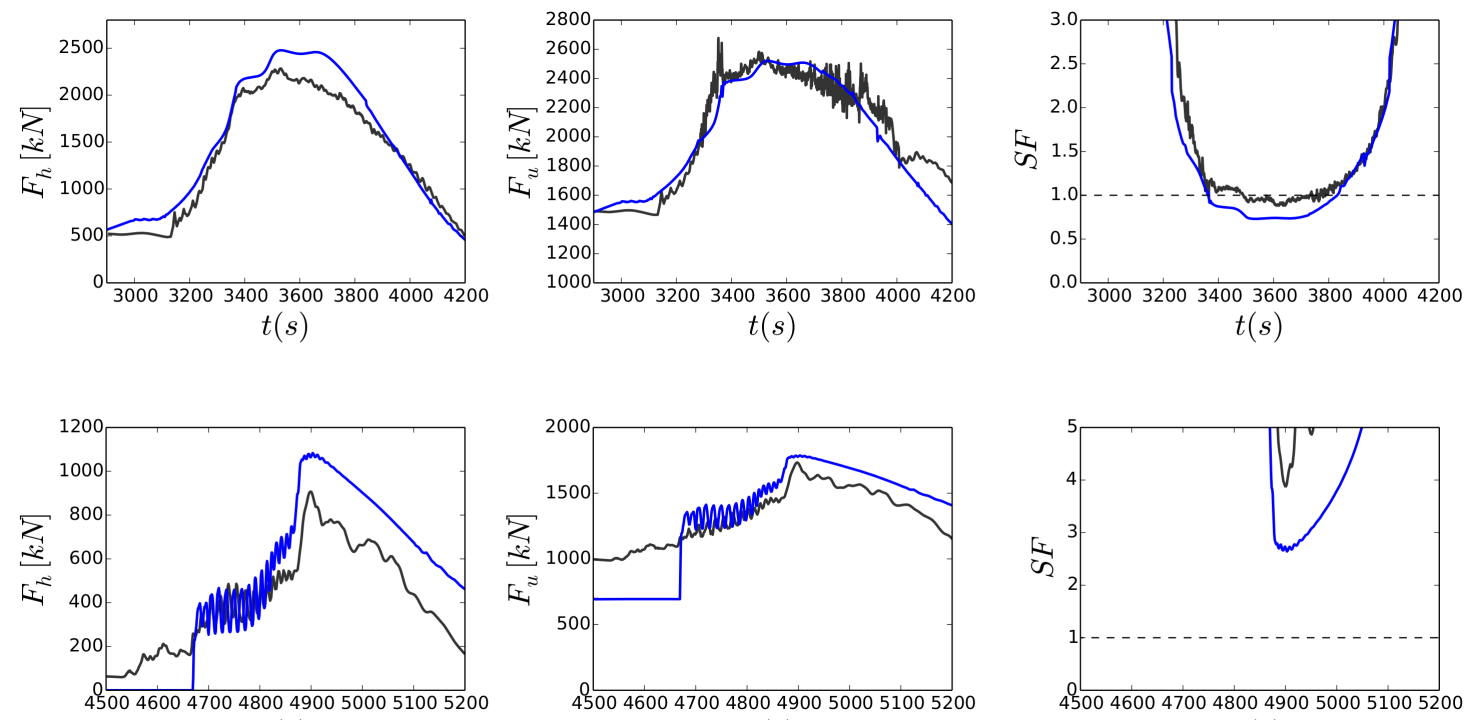

$t(s)$
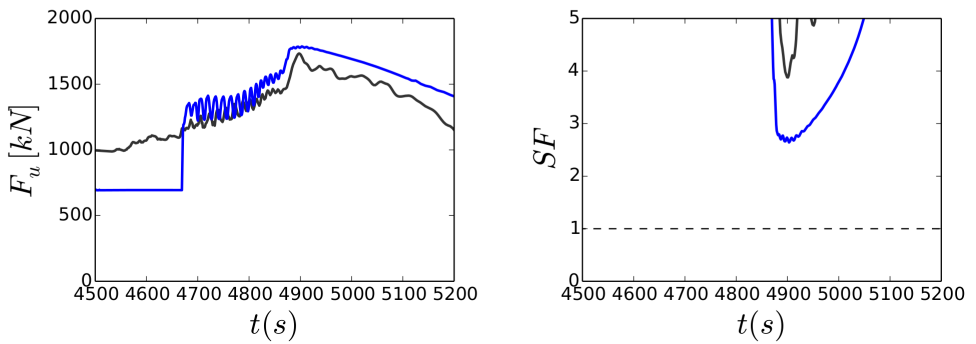

Fig. 10. Horizontal $\left(F_{h}\right)$ and uplift forces $\left(F_{u}\right)$ and safety factor values (S.F.) computed from THETIS results for the first (top panels) and second wave (bottom panels). Results obtained with BOSZ are displayed with blue lines. The dash line represents when the safety factor is below 1.0 (unstable condition). 

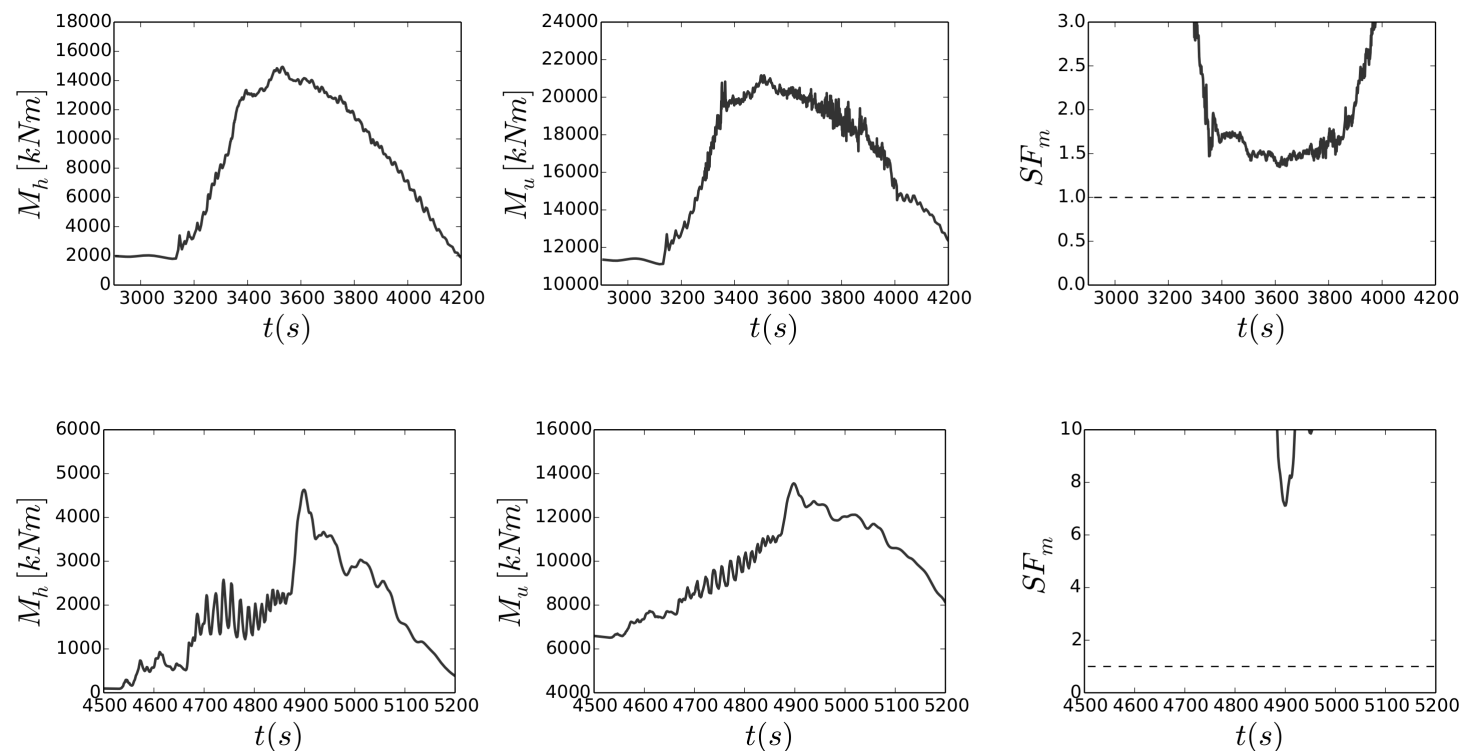

Fig. 11. Horizontal $\left(M_{h}\right)$ and uplift moments $\left(M_{u}\right)$ and safety factor values against overturning (S.F.m) computed from THETIS results for the first (top panels) and second wave (bottom panels). The dash line represents when the safety factor is below 1.0 (unstable condition). 
(a)

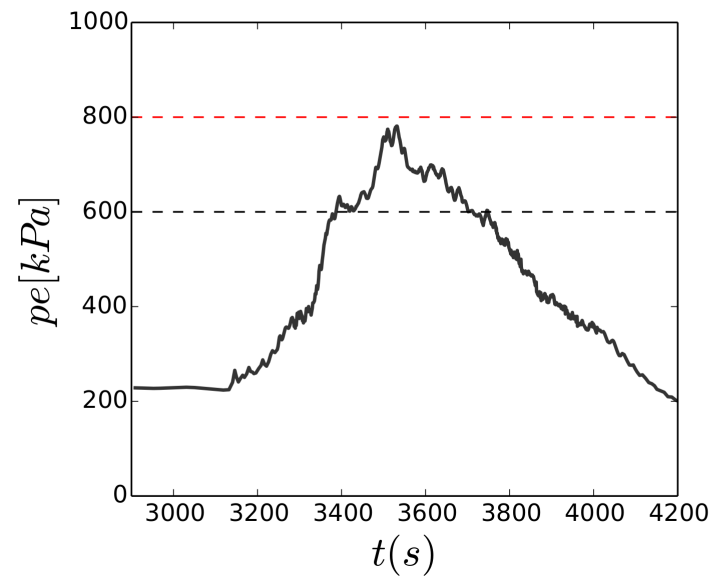

(b)

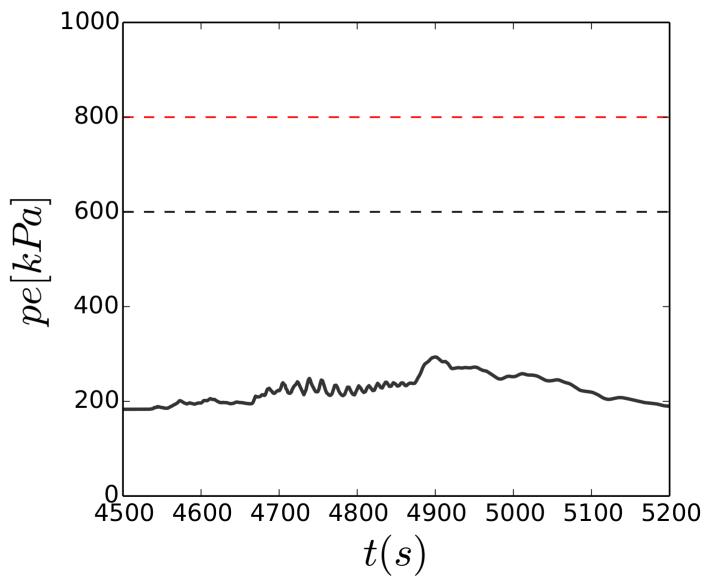

Fig. 12. Bearing pressure estimated with THETIS for the first (left) and second wave (right). Design bearing stress (- -) and critical bearing stress (- -). 


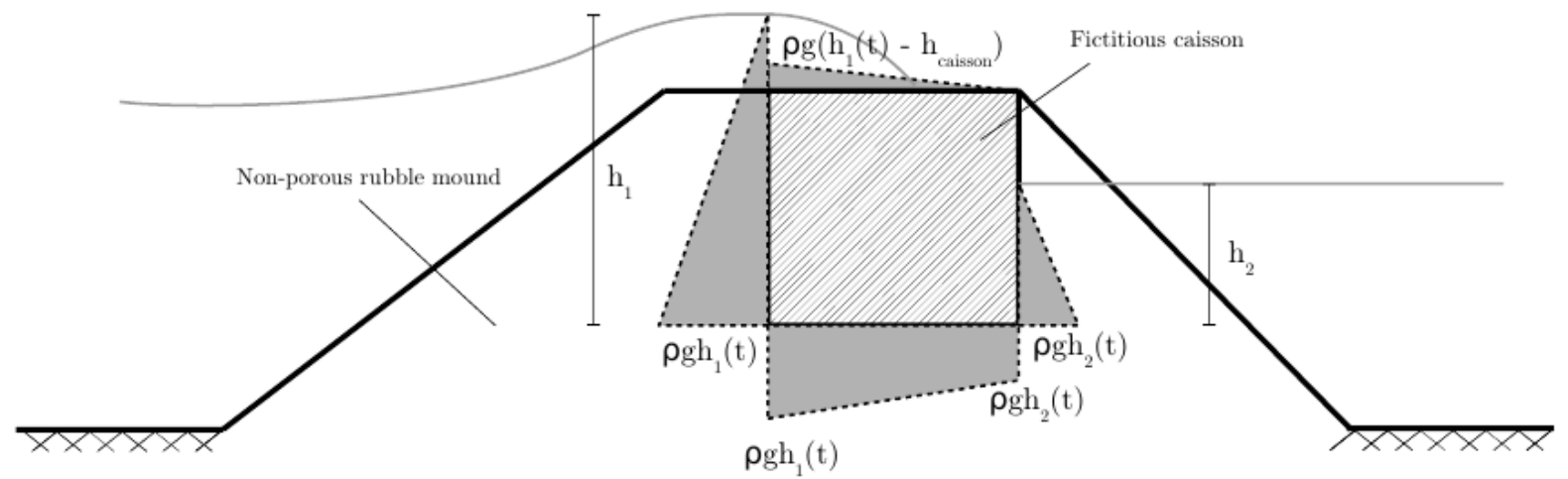

Fig. 13. Forces acting on the caisson breakwater assuming hydrostatic pressure. 